\title{
IMPROVED MAGNETIC REFRIGERATORS WITH Hi-Tc SUPERCONDUCTING MAGNETS
}

\section{Charles Gallo}

Superconix, Inc.

261 Fifth St East

Saint Paul MN 55101

April 1993

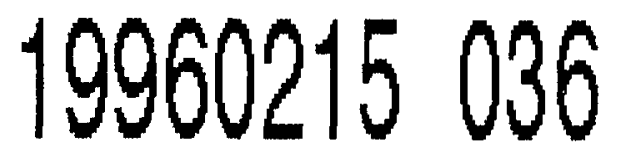

\section{Final Report}

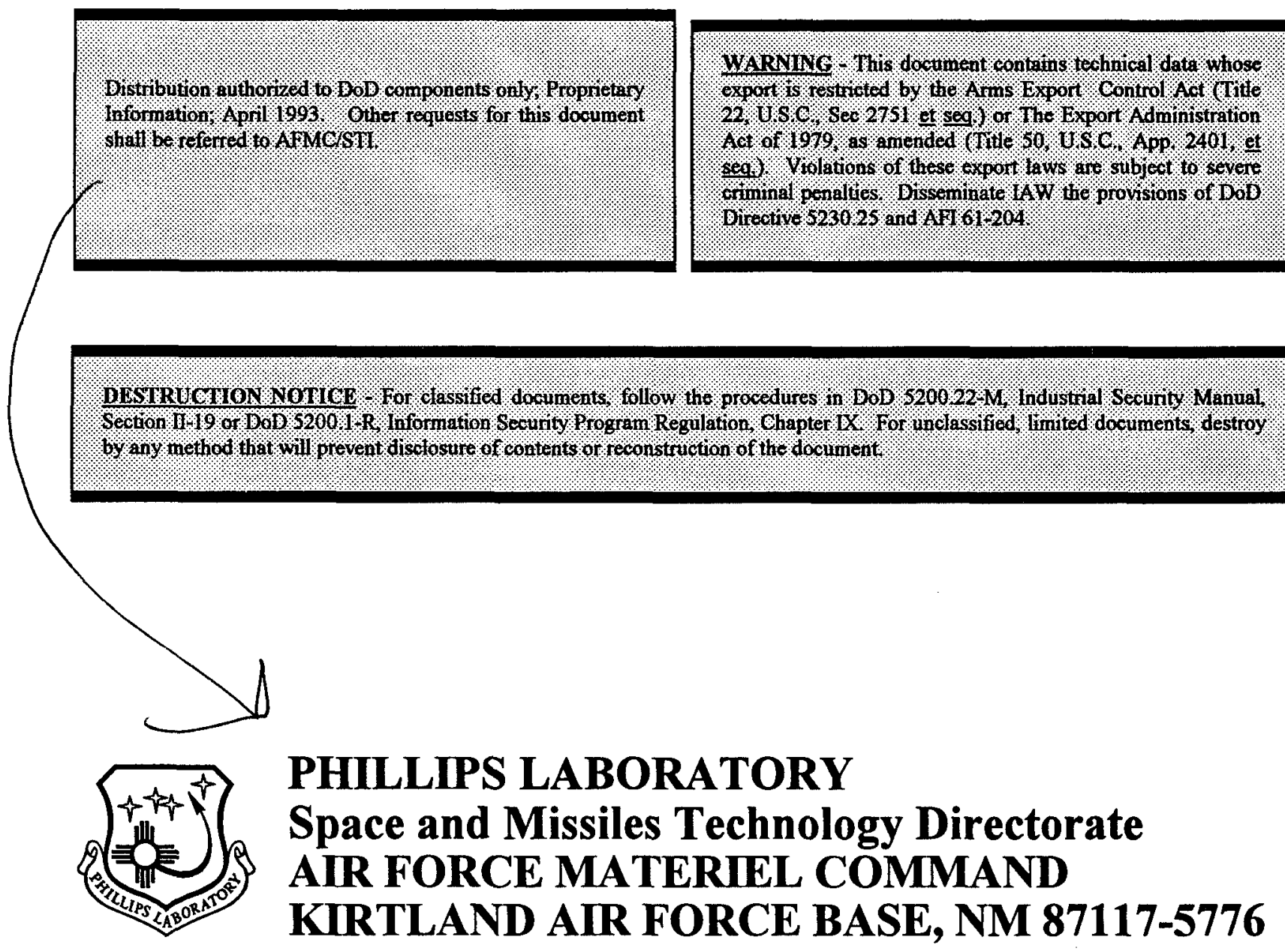




\section{UNCLASSIFIEL}

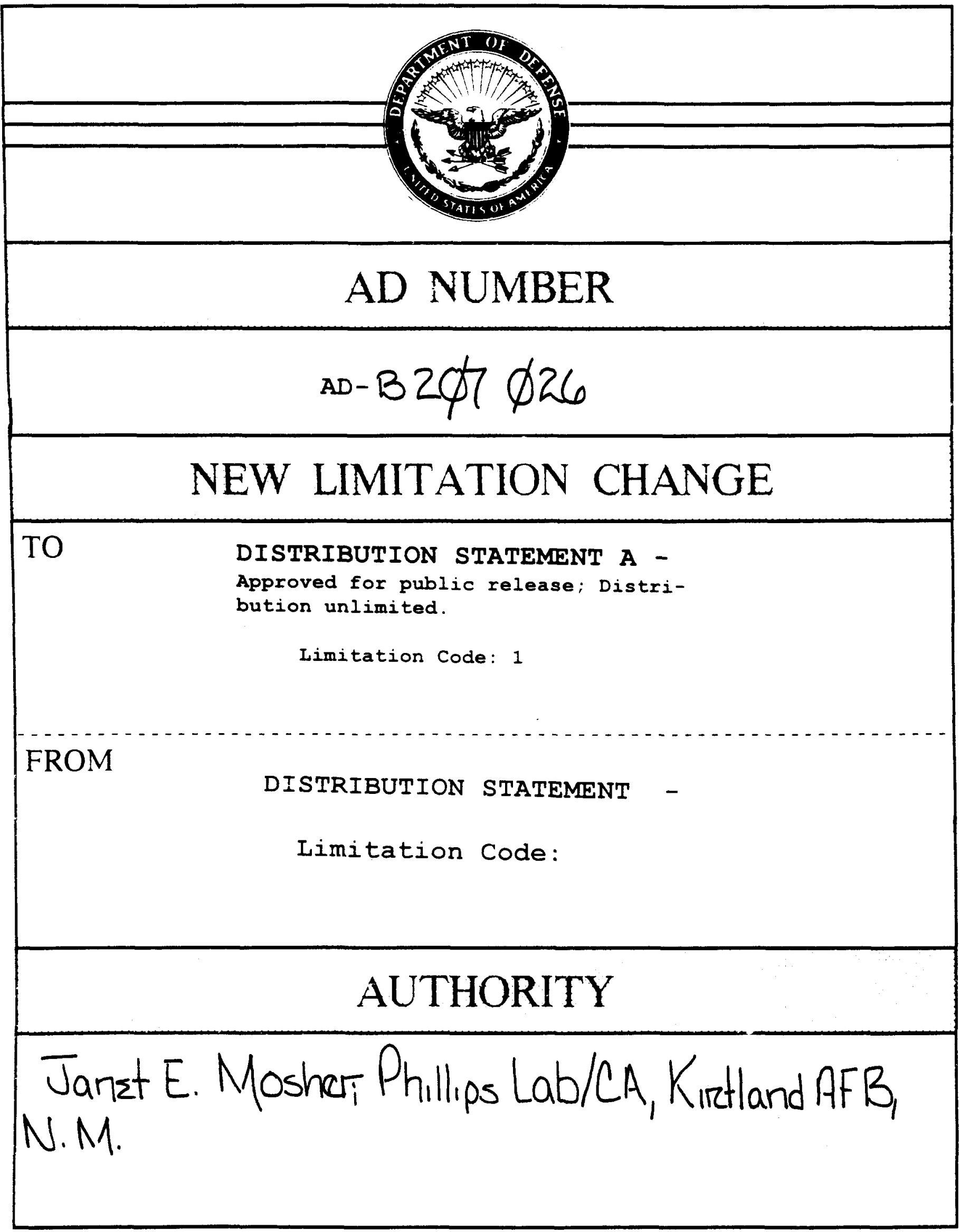

THIS PAGE IS UNCLASSIFIED 
PL-TR-93-1108

This final report was prepared by Superconix, Inc., St. Paul MN Contract F29601-93-C-0112 Job Order, 9991SB1R, with Phillips Laboratory, Kirtland Air Force Base, New Mexico. The Laboratory Project Officer-in-Charge was Marko Stoyanof (VTPT).

When Government drawings, specifications, or other data are used for any purpose other than in connection with a definitely Government-related procurement, the United States Government incurs no responsibility or any obligation whatsoever. The fact that the Government may have formulated or in any way supplied the said drawings, specifications, or other data, is not to be regarded by implication, or otherwise in any manner construed, as licensing the holder, or any other person or corporation; or as conveying any rights or permission to manufacture, use, or sell any patented invention that may in any way be related thereto.

This report has been authored by a contractor of the United States Government. Accordingly, the United States Government retains a nonexclusive royalty-free license to publish or reproduce the material contained herein, or allow others to do so, for the United States Government purposes.

This report contains proprietary information and shall not be either released outside the government, or used, duplicated or disclosed in whole or in part for manufacture or procurement, without the written permission of the contractor. This legend shall be marked on any reproduction hereof in whole or in part.

If your address has changed, if you wish to be removed from the mailing list, or if your organization no longer employs the addressee, please notify PL/VTPT, 3550 Aberdeen Ave SE, Kirtland AFB, NM 87117-5776 to help maintain a current mailing list.

This report has been reviewed and is approved for publication.

Marko 4 sto $f$

MARKO STOYANOF

Project Officer

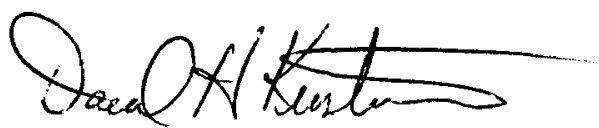

DAVID KRISTENSEN, Lt Col, USAF

Chief, Space Power and

Thermal Management Division
FOR THE COMMANDER

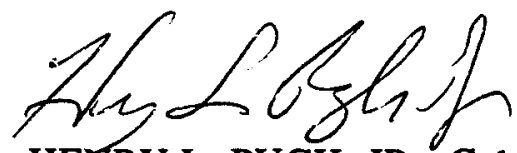

HENRY L. PUGH, JR., Col, USAF

Director of Space and Missiles Technology

DO NOT RETURN COPIES OF THIS REPORT UNLESS CONTRACTUAL OBLIGATIONS OR NOTICE ON A SPECIFIC DOCUMENT REQUIRES THAT IT BE RETURNED. 


\section{DRAFT SF 298}

1. Report Date (dd-mm-yy)

April 1993
2. Report Type

Final

3. Dates covered (from... to )

$11 / 92$ to $4 / 93$

4. Title \& subtitle

Improved Magnetic Refrigerators With Hi-Tc

Superconducting Magnets

\section{5a. Contract or Grant \#}

F29601-93-C-0112

5b. Program Element \# 62601F

\section{Author(s)}

Charles Gallo

\section{5c. Project \# 9991}

5d. Task \# SB

5e. Work Unit \# $1 R$
7. Performing Organization Name \& Address

Superconix, Inc.

261 Fifth St East

Saint Paul, MN 55101

9. Sponsoring/Monitoring Agency Name \& Address

Phillips Laboratory

3550 Aberdeen Ave SE

Albuquerque, NM 87117-5776
8. Performing Organization Report \#
10. Monitor Acronym

11. Monitor Report \#

PL-TR-93-1108

12. Distribution/Availability Statement Distribution authorized to DoD components only; Proprietary Information; April 1993; Other requests for this document shall be referred to AFMC/STI.

13. Supplementary Notes

14. Abstract To produce pre-formed thick-film Hi-Tc superconducting magnets with improved critical current for magnetic refrigerators, the Hi-Tc superconducting powder was coated with a thin film of beneficial metal (s) ( $\mathrm{Ag}, \mathrm{Pb}, \mathrm{Nb})$ before fabrication. It was anticipated that the metallic bonding between the Hi-Tc superconducting grains would overcome the usual "weak-links" that limit the superconducting current. This might be particularly effective with Lead and Niobium since these low temperature superconductors have long coherence lengths. After fabrication and heat treatment, the superconducting properties of the thick-films were measured, particularly the critical current (Jc). Regarding improvements in Jc of Bi2Sr2CaCu2Ox thick films, Ag-coating gave improvements of $+131 \%$. However, for Bi1.8Pb.4Sr2Ca2Cu30x thick-films, Ag-coating decreased Jc -29\%, Nb-coating decreased Jc $-48 \%$, Ag+Nb-coating decreased Jc-52\%, and Pb-coating chemically deteriorated the BiPb2223 superconductor.

15. Subject Terms superconductor, thin film

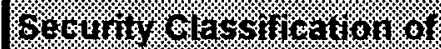

16. Report Unclassified
17. Abstract Unclassified
18. This Page Unclassified
19.

Limitation of Abstract Limited
20. \# of Pages

46
21. Responsible Person (Name and Telephone \#)

Marko Stoyanof (505) 846-2660 


\title{
GOVERNMENT PURPOSE LICENSE RIGHTS (SBIR PROGRAM)
}

\author{
Contract Number: F29601-93-C-0112 \\ Contractor: Superconix, Inc. \\ St. Paul, MN
}

For a period of four (4) years after delivery and acceptance of the last deliverable item under the above contract, this technical data shall be subject to the restrictions contained in the definition of "Limited Rights" in DFARS clause at 252.227-7013. After the four-year period, the data shall be subject to the restrictions contained in the definition of "Government Purpose License Rights" in DFARS clause at 252.227-7013. The Government assumes no liability for unauthorized use or disclosure by others. This legend shall be included on any reproduction thereof and shall be honored only as long as the data continues to meet the definition on Government purpose license rights. 
CONTENTS

Page

COVER PAGE

REPORT DOCUMENTATION PAGE (DD FORM 1473)

i/ii

CONTENTS

iii

LIST OF FIGURES

iv

LIST OF TABLES

$\mathbf{v}$

SUMAARY

1

INTRODUCTION/OBJECTIVES

2

EXPERIMENTAL ARRANGEMENT

6

EXPERIMENTAL MEASUREMENTS/RESULTS

Ag-COATED Bi2212 Bi-Tc SUPERCONDOCTORS

Ag-COATED BiPb2223 Bi-Te SUPERCONDDCTORS

LOW TC - COATED BIPb2223 Hi-TC SUPERCONDUCTORS

$\mathrm{Nb}-\mathrm{COATED}$ BiPb2223 Bi-Tc SUPERCONDDCTORS

$\mathrm{Ag}+\mathrm{Nb}-\mathrm{COATED}$ BIPb2223 Bi-Tc SUPERCONDUCTORS

$\mathrm{Pb}$-COATED BiPb2223 Hi-TC SUPERCONDDCTORS

NbN LO-TC SUPERCONDUCTOR

CONCLOSIONS/RECOMENDATIONS

27

TABLES

28-37 
FIGURES

Figure

Page

1. Novel "sandwich" method of fabricating encapsulated 3 Bi-Tc thick films and preformed magnets.

2. Apparatus for coating superconducting particles with metal films: rotating drum.

3. Apparatus for coating superconducting particles with metal films: rotating/vibrating dish.

4. Magnetic susceptibility vs temperature for Ag-coated Bi2212 thick-film Ag-foil sandwich.

5. Magnetic hysteresis loop for Ag-coated Bi2212 thick-film Ag-foil sandwich.

6. Critical current density (Jc) vs magnetic field for uncoated and Ag-coated Bi2212 thick-film Ag-foil sandwich.

7. Trapped flux vs time for Ag-coated Bi2212 thick-film Ag-foil sandwich.

8. Trapped flux ys applied magnetic field for Ag-coated Bi2212 thick-film Ag-foil sandwich.

9. Critical current density (Jc) vs magnetic field for uncoated and Ag-coated BiPb2223 thick-film Ag-foil sandwich.

10. Critical current density (JC) vs magnetic field

for various thicknesses of $\mathrm{Ag}$-coated BiPb2223 powder of two different particle sizes ( $-3 \mathrm{um} \& 15 \mathrm{um}$ ) fabricated into thick-film Ag-foil sandwiches.

11. Magnetic susceptibility vs temperature for $\mathrm{Nb}$-coated BiPb2223 thick-film Ag-foil sandwich.

12. Critical current density (Jc) vs magnetic field for Nb-coated BiPb2223 thick-film Ag-foil sandwich.

13. Trapped flux vs applied magnetic field for Nb-coated BiPb2223 thick-film Ag-foil sandwich.

14. Magnetic susceptibility vs temperature for uncoated and $\mathrm{Pb}$-coated BiPb2223 powder.

15. Critical current density (Jc) vs magnetic field for $\mathrm{Pb}$-coated BiPb2223 thick-film Ag-foil sandwich. 


\section{TABLES}

Table

Page

1. Tabular description of $\mathrm{Hi-Te}$ superconducting powders coated with a thin film of different metals ( $\mathrm{Ag}, \mathrm{Nb}, \mathrm{Pb}$ ).

2. Tabular description of measurements on Hi-Tc superconducting powders (coated \& uncoated).

3. Tabular description of measurements on substrates 30 coated with superconducting (Nb \& NbN) films.

4. Tabular description of the preparation of Hi-Tc superconducting thick-film $\mathrm{Ag}$-foil sandwich samples (thick-film pre-formed magnets).

5. Tabular summary of measurements on Hi-TC superconducting thick-film magnets. 


\section{SOMMARY}

The overall objective is to produce pre-formed thick-film Hi-Tc superconducting magnets with improved critical current for magnetic refrigerators. To achieve this objective, the Bi-Tc superconducting powder was coated with a thin film of beneficial metal ( $\mathrm{s}$ ) ( $\mathrm{Ag}, \mathrm{Pb}, \mathrm{Nb}$ ) before fabrication into pre-formed thickfilm magnets. It was anticipated that the resultant metallic bonding between the $B i-T c$ superconducting grains would overcome the usual "weak-links" that limit the superconducting current. This might be particularly effective with Lead and Niobium since these metals are superconducting with long coherence lengths at low temperatures. After fabrication and heat treatment, the following superconducting properties of the thick-films were measured.

(1) Superconducting transition temperature (Tc).

(2) Critical superconducting current (Jc).

(3) Trapped magnetic flux.

Regarding improvements in $\mathrm{Jc}$ of $\mathrm{Bi}_{2} \mathrm{Sr}_{2} \mathrm{CaCu}_{2} \mathrm{O}_{x}$ thick films, $\mathrm{Ag}-$ coating gave improvements of $\boldsymbol{+ 1 3 1 \%}$. However, for

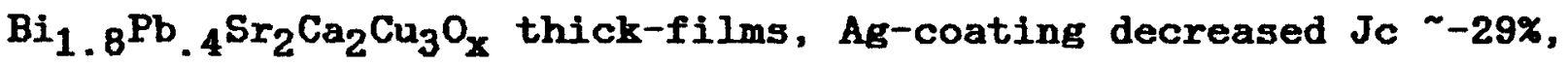
$\mathrm{Nb}$-coating decreased $\mathrm{Jc} \sim-48 \%, A g+\mathrm{Nb}$-coating decreased $\mathrm{Jc} \sim 52 \%$, and $\mathrm{Pb}$-coating chemically deteriorated the BiPb2223 superconductor. The Ag-coating undoubtedly improved the ductility and strain tolerance of the fabrication and would be useful in wire technology, but that was not the objective of this project. The improvements in Jc are too marginal for further pursuit in a Phase 2 project at this time, but further efforts with other materials is justified on an exploratory basis in future Phase 1 efforts. 


\section{INTRODUCTION/OBJECTIVES}

Magnetic refrigerators are very promising for many applications due to their long-life and subdued vibration. However, the size, weight, cost and refrigeration efficiency will depend on the magnet characteristics. Conventional copper-coil electromagnets are unrealistic because of their high power consumption, large size, heavy weight and need for cooling. Thus, superconducting magnets are under consideration to alleviate these problems, particularly the power consumption. Conventional "low temperature" superconducting magnets have the disadvantage of required operation at very low temperatures which reintroduces size, weight, cost and inefficiency burdens. In principle, the new "high temperature" superconductors would be very beneficial, but there are problems with fabricating these "Bi-Tc" ceramic materials into flexible wire with high current capacity.

Our innovations yield Hi-Tc superconducting magnets by utilizing "pre-formed thick-film Hi-Tc" fabrications with high critical currents that circumvent the Bi-Tc wire problems. Our proprietary magnet fabrications can also be magnetically pumped, thus eliminating the wire problems of winding, anchoring, contact resistance and thermal gradients. Our innovations briefly follow.

(1) A novel method of fabricating encapsulated (Bi.Pb)2Sr2Ca2Cu30X Bi-Te superconducting thick films is shown in Figure 1 which yields BIGB Tc (110K) and reasonably BIGH Jc. This proprietary encapsulation technique circumvents the problems with $\mathrm{Pb}$-escape and retrograde densification that usually adverseIy affects Tc and Jc in this Bi2223 superconducting material. Our previous studies also revealed that the anisotropic superconducting grains were aligned with the desireable ab-plane oriented parallel to the Ag substrate in the direction of maximum current flow. 


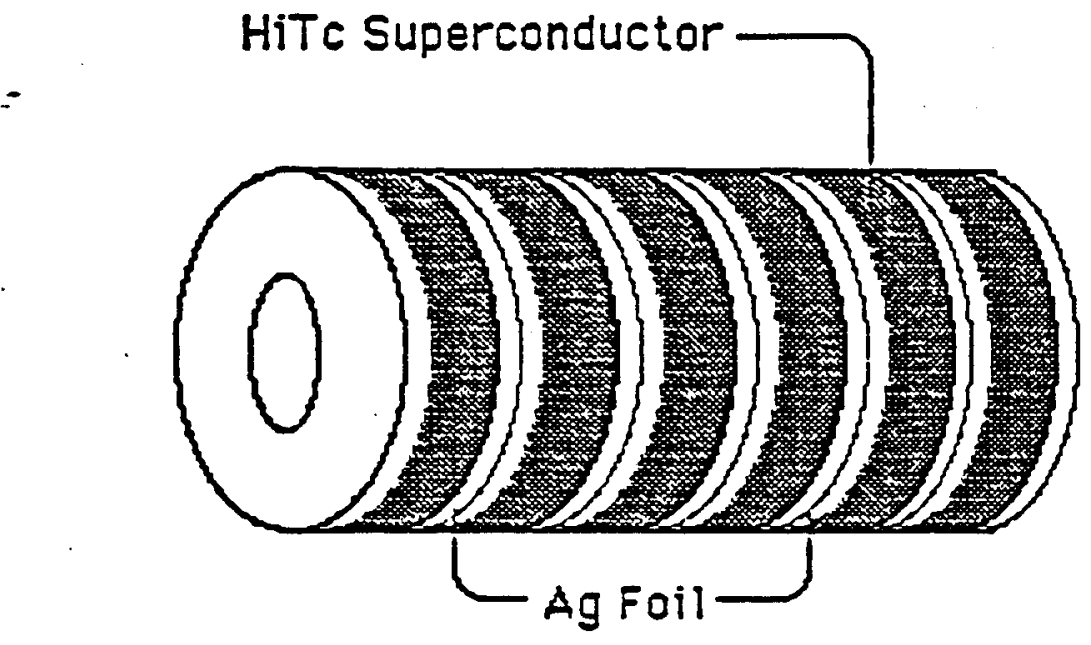

Figure 1. Novel "sandwich" method of fabricating encapsulated Bi-Tc thick films and preformed magnets. For Bi-Tc $\mathrm{Bi} . \mathrm{Pb} .2223$ thick films, this encapsulation technique circumyents $\mathrm{Pb}-$ loss and retrograde densification and yields BIGB Tc (110K) and reasonably BIGH Jc with Erain aligament. By cascading these circular annular thick-film sandwiches, a Bi-Tc superconducting magnet can be constructed as shown. These "washer-shaped" ring sandwiches can carry a higher total current because the "thickness" can be conveniently made larger. The superconducting current and accompanying magnetic field can be induced by "flux-pumping" schemes. 
(2) The magnets can be constructed with these pre-formed Hi-Tc thick films by two different techniques, one of which is shown in Figure 1. These novel designs circumvent problems with brittle low-current Bi-Tc wires.

(3) Novel "flux-pumping" schemes can be used to magnetically induce current in the pre-formed magnets which do not require brittle wire, electrical leads or high current power supplies. A conceptual scheme is shown in our original proposal which also contains one possible configuration relevant to a magnetic refrigerator.

(4) To further improve the superconducting critical currents (Jc), the inter-granular weak-link problem may be minimized by coating the BiPb2223 superconducting particles with thin films of compatible metal(s) prior to fabrication into BiPb2223 thick films. Since the Hi-Tc superconductors are chemically complex oxide materials, the grain boundaries often contain undesireable oxides that form "weak-1inks" that limit the superconducting current. The metal coatings on the grains may circumvent this problem. This is particularly troublesome in the chemically difficult BiPb2223 material which decomposes irreversibly at low temperatures $845 \mathrm{C}$ substantially below its effective sintering/melting temperature. Since the BiPb2223 material cannot be melt-processed or sintered to yield high density compacts with high Jc, the metal coating on the grains may serve as effective "electrical cement" at the lower sintering temperatures. THIS IS THE MAJOR TASK OF THIS CONTRACT.

(5) Further improve Jc by ion irradiation of Bi2223 superconducting particles to improve intra-granular flux-pinning, but this is beyond Phase 1 and will be attacked in the future.

(6) Use Hi-Tc superconductors as the magneto-caloric refrigeration medium with higher efficiency than the usual paramagnetic/ferromagnetic magneto-caloric refrigeration materials. This novel concept is the subject of another SDIO/Army Phase 1 SBIR contract. 
The overall objective this SDIO/Air Force SBIR Contract is to produce pre-formed thick-film Bi-Tc superconducting magnets with improved critical current for magnetic refrigerators. To achieve this objective, the Bi-Tc superconducting powder was coated with a thin film of beneficial metal(s) (ex, $\mathrm{Ag}, \mathrm{Pb}, \mathrm{Nb}$ ) before fabrication into pre-formed thick-film magnets. The following technical tasks were performed.

(1) Bi-Tc superconducting Bi2212 and BiPb2223 powder particles were coated with compatible metallic thin films $(\mathrm{Pb}, \mathrm{Ag}$, $\mathrm{Nb}$ ).

(2) With the metal-coated Bi-Tc superconducting powders, encapsulated Hi-TC thick-film magnets were fabricated.

(3) The superconducting transition temperature (Tc), critical current density (Jc) and "trapped" magnetic fields/currents of the encapsulated Hi-Tc superconducting thick films were measured.

Since the above results were NOT significantly beneficial for increasing the critical current (Jc), possible pursuit of a Phase 2 proposal and associated tasks was abandoned. 


\section{IXPERIMENTAL ARRANGEMENT}

To achieve the objective of higher Jc, the first step is to coat the $\mathrm{Bi}$-Tc superconducting powder with a thin layer of beneficial metal(s) (ex, $\mathrm{Ag}, \mathrm{Pb}, \mathrm{Nb}$ ) before fabricaton into thick-film preformed magnets. For thin-film coating the Hi-Tc powder, Figure 2 shows the sputtering equipment which was assembled and tested. The superconducting powder particles were tumbled inside a rotating drum inside a vacuum system. Sputtering of the metal film onto and around the surface of the superconducting particles was achieved from a tubular metal sputtering target mounted along the axis of the rotating drum. This system (Figure 2) proved ONSATISFACTORY for several reasons with the following most critical. The powders stuck tightly to the inner drum surface and did NOT tumble as desired for uniform coating. The powder sticking is probably due to triboelectric effects (especially aggravated in vacuum). A possible solution was the introduction of a "scraper blade" on the inside of the drum, but this approach seemed to introduce more problems than solutions.

Thus, we switched to a different approach using a "rotating vibrator" as shown in Figure 3. The powder is placed in a shallow rotating/vibrating dish beneath the sputtering target. This worked, although lumps in the Bi-TC powder were problematic. This technique worked better for larger size particles than the smaller particles which had a tendency to stick together and not vibrate/tumble as effectively. 


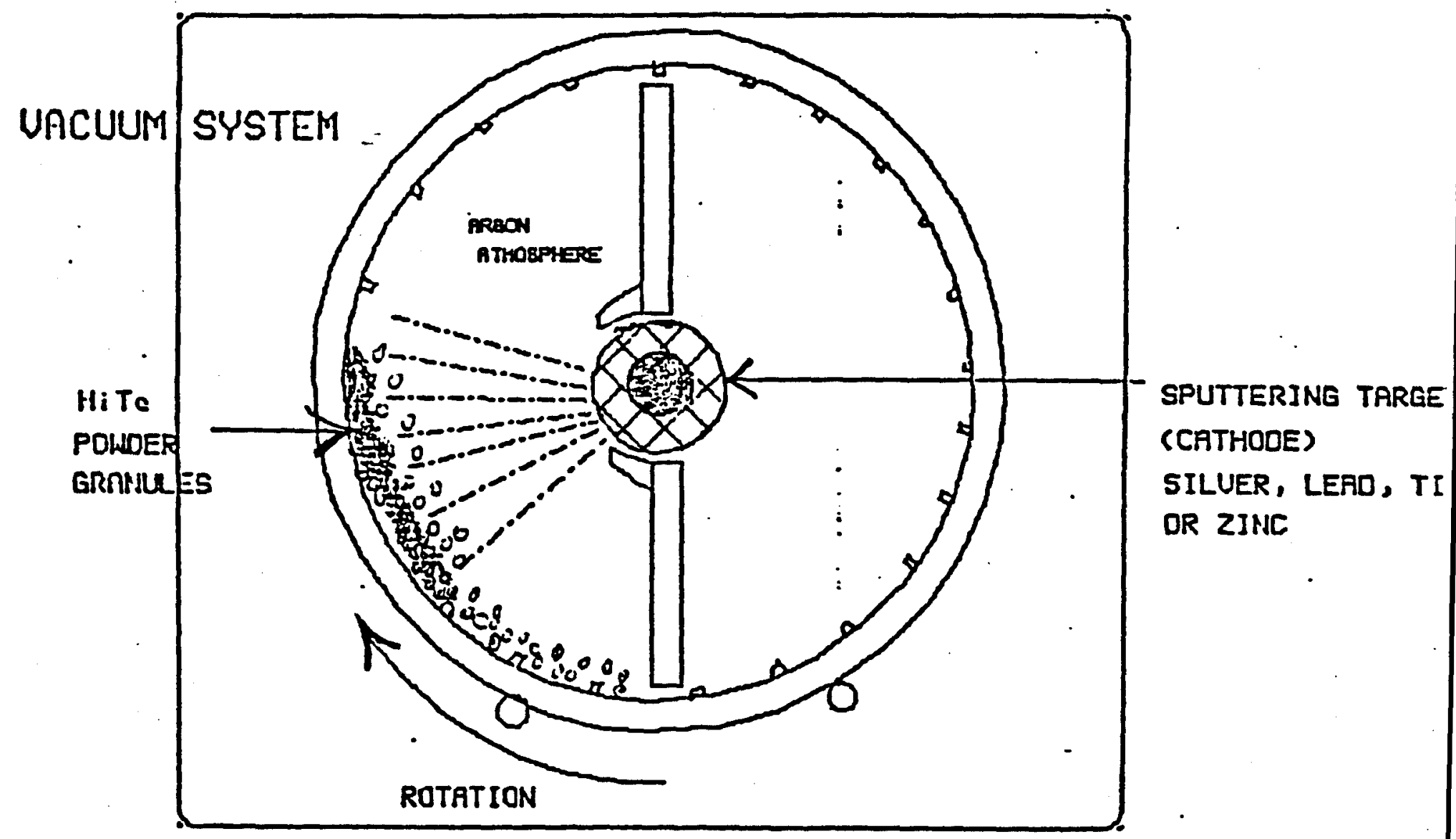

Figure 2. Apparatus for coating superconducting particles with metal films: rotating drum. The superconducting powder particles (ex, Bi2Sr2Ca2Cu30X) were tumbled inside a rotating drum inside a vacuum system. Sputtering of the metal film onto and around the surface of the superconducting particles was achieved from a tubular metal sputtering target mounted along the axis of the rotating drum. 


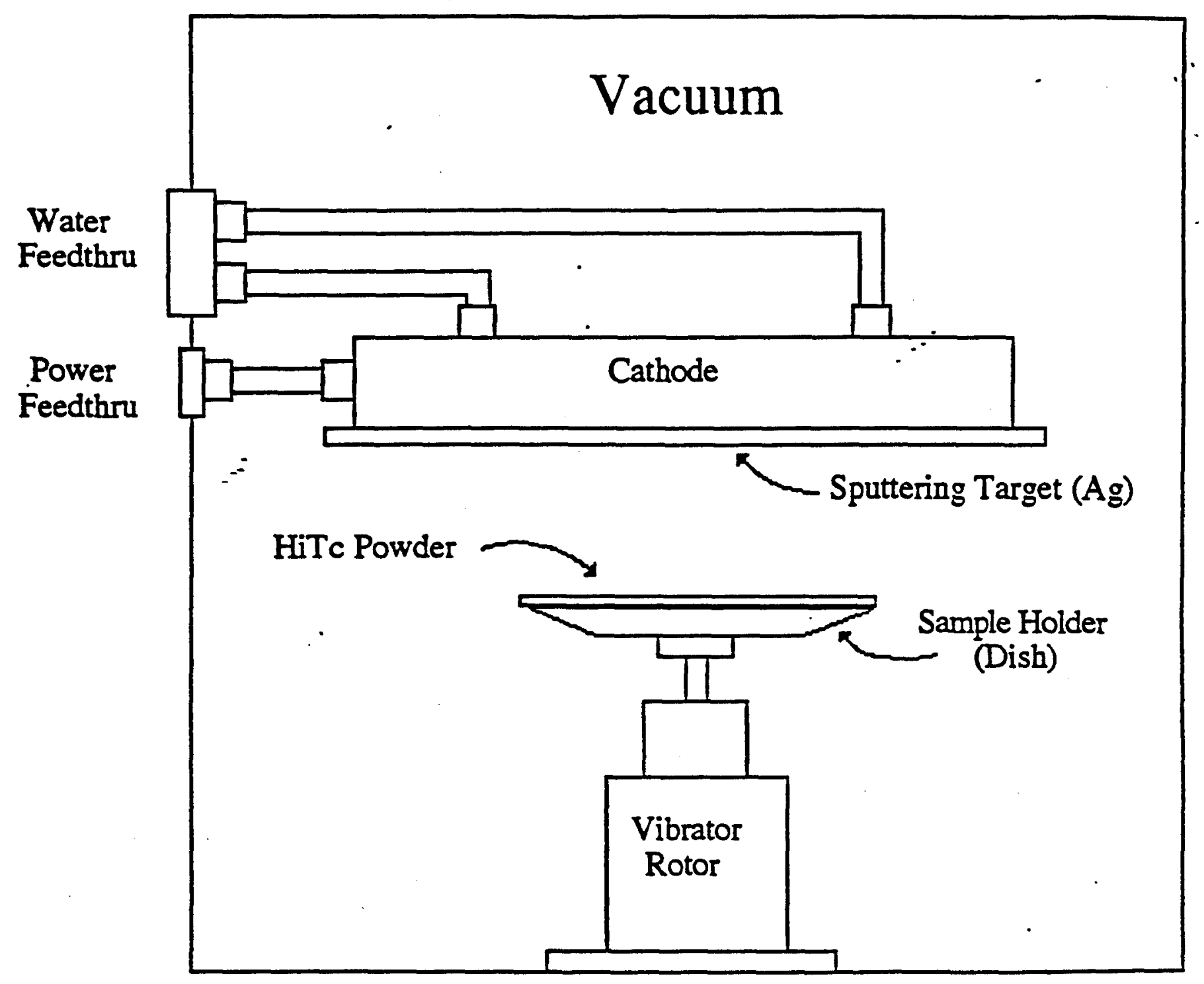

Figure 3. Apparatus for coating superconducting particles with metal films: rotating/vibrating dish. The superconducting powder particles were contained in a shallow dish which was rotated and vibrated beneath a sputtering target. This produced a metallic coating around the surface of the Bi-Tc particles. 


\section{EXPERIMENTAL MEASUREMENTS/RESULTS}

The Bi-Tc superconducting powders that were coated with various metals are described in Table 1 and subsequent measurements of their superconducting transition temperature Tc via magnetic susceptibility in a SQOID magnetometer in Table 2. During sputtering, a metal film was also deposited on an auxiliary substrate for monitoring the film thickness and its superconducting transition temperature Tc as described in Table 3.

After metal-coating of the Hi-Tc powder, thick-film Ag-foil sanwiches (thick-film pre-formed magnets) were pressed and sintered at various time/temperatures in various anneal gases as described in Table 4. Table 5 describes measurements of the superconducting properties as follows.

(1) Superconducting Transition Temperature (Tc). This was measured via the magnetic susceptibility on a dC SQOID magnetometer.

(2) Critical Superconducting Current (Jc). Again with the SQUID magnetometer, the magnetic hysteresis loop [magnetization (M) vs applied magnetic field (B)] was measured at constant temperature. The critical current density (Jc) was then calculated from the Bean model via

$$
J c=20 d M / a(1-a / 3 b)
$$

where $d M$ is the width of the magnetic hysteresis loop, and $a \& b$ are the lateral sample dimensions.

(3) Trapped Magnetic Flux. This was measured on the thickfilm sandwich magnets in the SQOID magnetometer as follows. First the sample temperature was raised above $\mathrm{Tc}$, and then a steady magnetic field (B) was applied as the temperature was decreased below Tc to the desired steady temperature. Then, at constant temperature, the magnetic field is turned off and the magnetic moment ("trapped flux") of the superconductor (due to the per- 
sistent superconducting current) was measured as a function of time. As expected, the persistent superconducting current was maintained with time as desired for "flux-pumping" the magnets without use of an injected current. This procedure was repeated for different magnetic fields to obtain a graph of the "trapped flux" vs applied magnetic field. This graph defines the useful magnetic range over which the superconductor mas be used in the "flux-pumping trapped-flux" mode. This procedure was repeated at various temperatures to determine the useful temperature/magnetic range over which the superconductor may be used in the "fluxpumping trapped-flux" mode.

The great multitude of samples and measurements are succinctly described in Tables 1-5. In the remainder of this section, we will concentrate ONLY on those CONCLUSIVE results that have GENERIC significance.

\section{Ag-COATED Bi2212 Hi-TG SUPERCONDUCTORS}

The most interesting data for Ag-coated Bi2sr2CaCu20x thick-films is shown in Figures 4-8. The magnetic susceptibility curve (Fig 4) indicates an encouraging Tc=90K. Figure 5 shows the magnetic hysteresis loop at $10 \mathrm{~K}$ from which the critical current density (JC) (Fig 6) was calculated from the Bean model (Eq 1). It can be seen that an improvement in $\mathrm{Jc}^{\sim}+131 \%$ was achieved with Ag-coating. As desired, the trapped flux showed a very slow time decay under all conditions and the data is shown in Figure 7 for $10 \mathrm{~K}$ and 1,000G. In Figure 8, the trapped flux vs applied magnetic field peaked at $1,000 \mathrm{G}$ wich indicates that this sample magnet would not be useful in flux-pumped magnetic fields above 1,000G. 
Susceptibility vs Temperature Ag-coated Bi2212 (H=20G) sample 7/2/93A

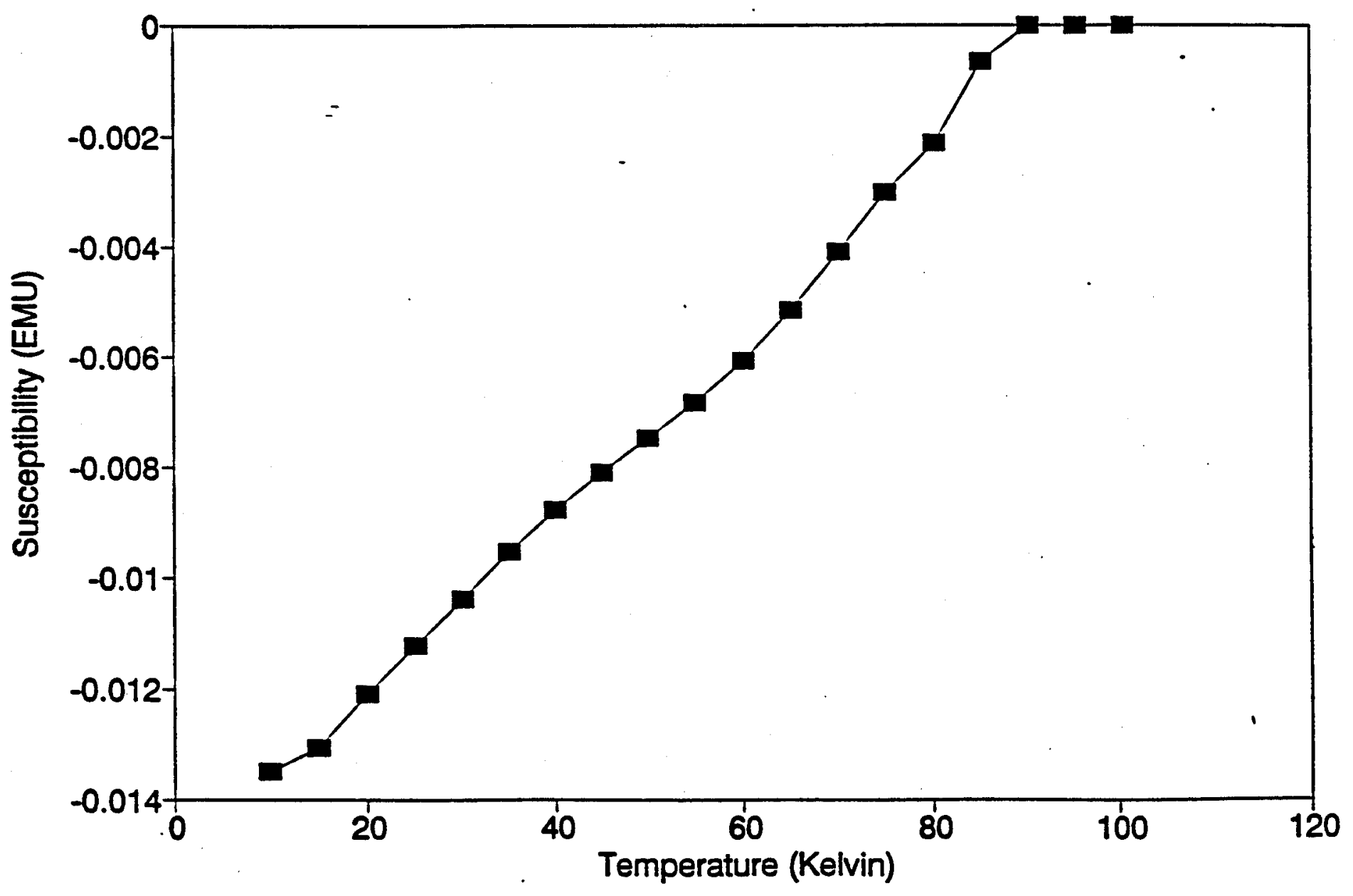

Figure 4. Magnetic susceptibility ys temperature for Ag-coated Bi2212 thick-film Ag-foil sandwich. Sample 7/2/93A. 


\section{Magnetization vs Applied Field Ag coated Bi2212, sample 7/2/93A. .}

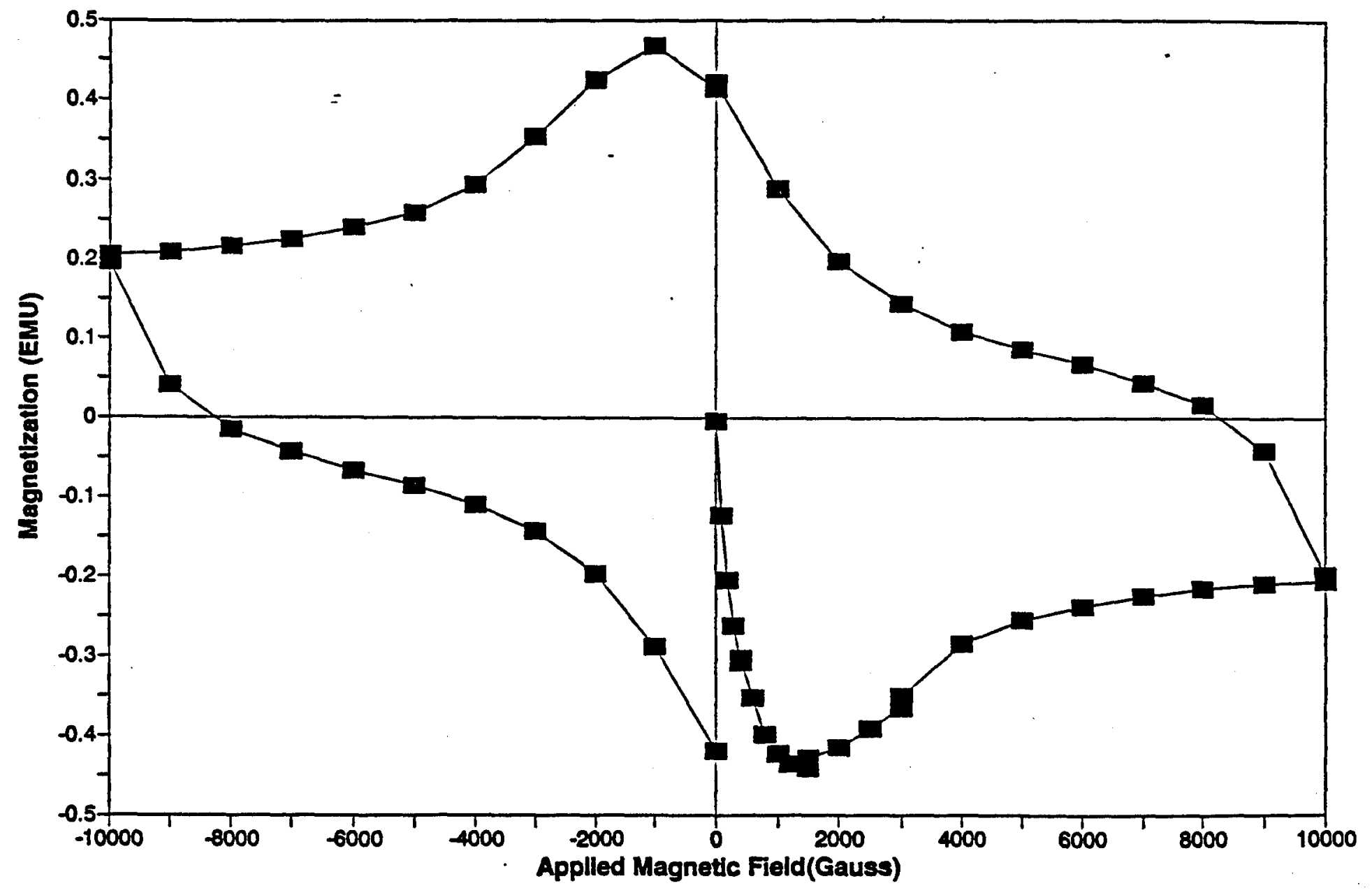

Figure 5. Magnetic hysteresis loop for Ag-coated Bi2212 Thick-film Ag-foil sandwich. Sample 7/2/93A. $T=10 \mathrm{~K}$. 


\section{JC vs H \\ $\mathrm{Bi} 2212(\mathrm{~T}=10 \mathrm{~K})$}

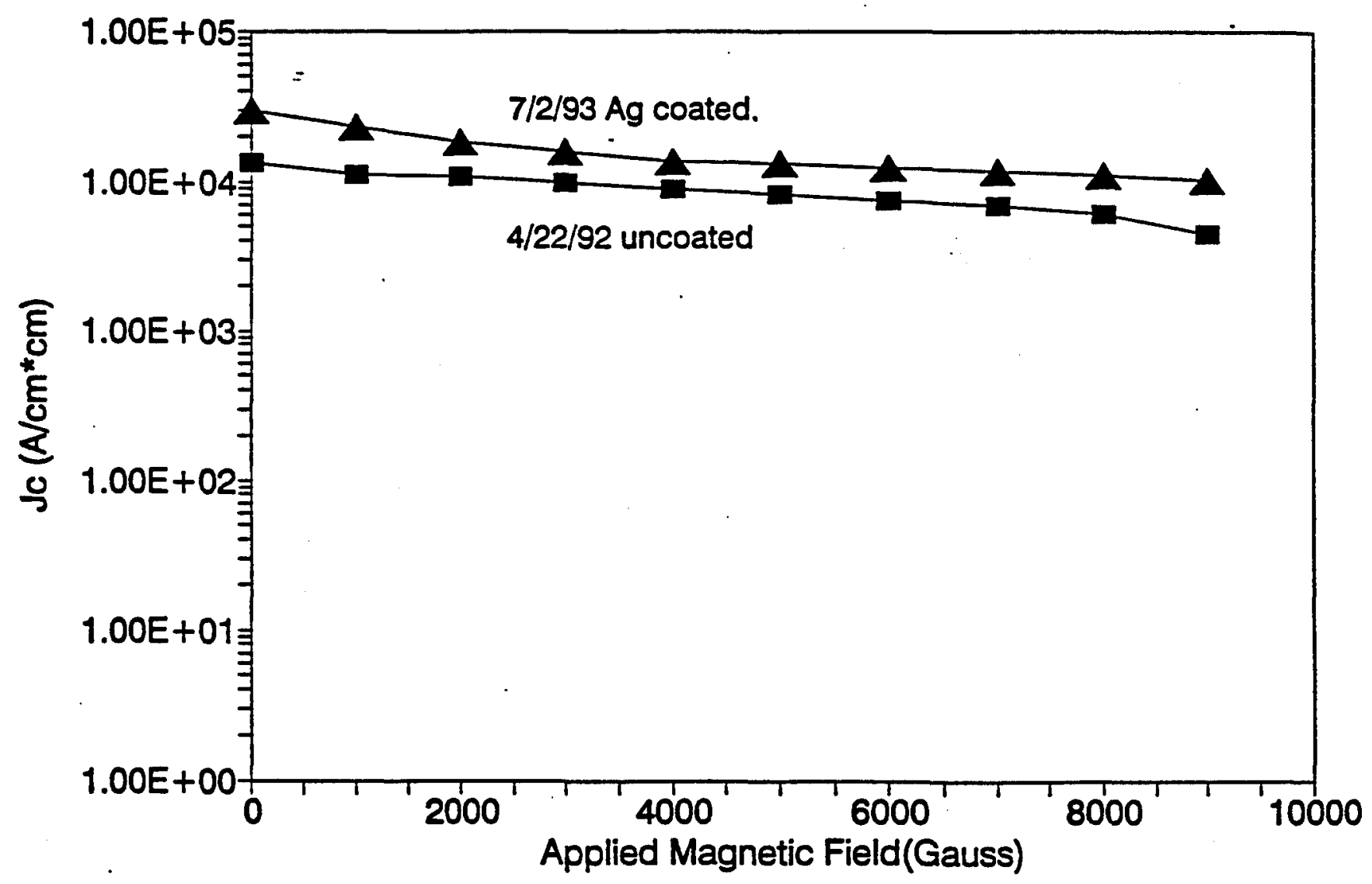

Figure 6. Critical current density (Jc) vs magnetic field for uncoated and $\mathrm{Ag}$-coated Bi2212 thick-film $\mathrm{Ag}$-foll

sandwich. Oncoated sample 4/22/92. Ag-coated sample 7/2/93A. $T=10 \mathrm{R}$. 


\section{Trapped Flux vs Time}

Ag-coated Bi2212 sample 7/2/93A

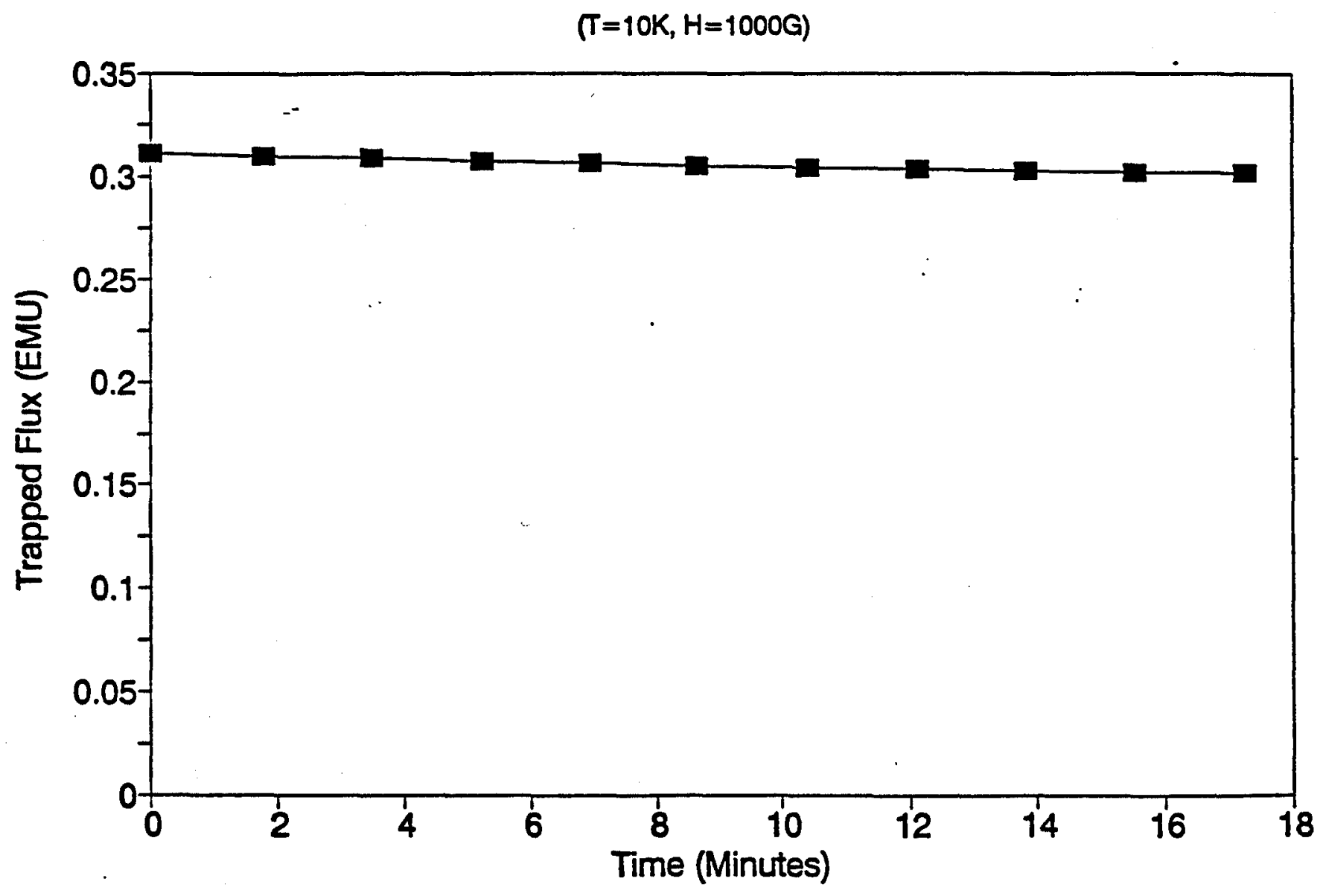

Figure 7. Trapped 1 lux vs time for Ag-coated Bi2212 thick-film Ag-foil sandwich. Sample 7/2/93A. $T=10 K$. $B=1,000 G$. 


\section{Trapped Flux vs Applied Field \\ Ag-coated Bi2212 sample 7/2/93A}

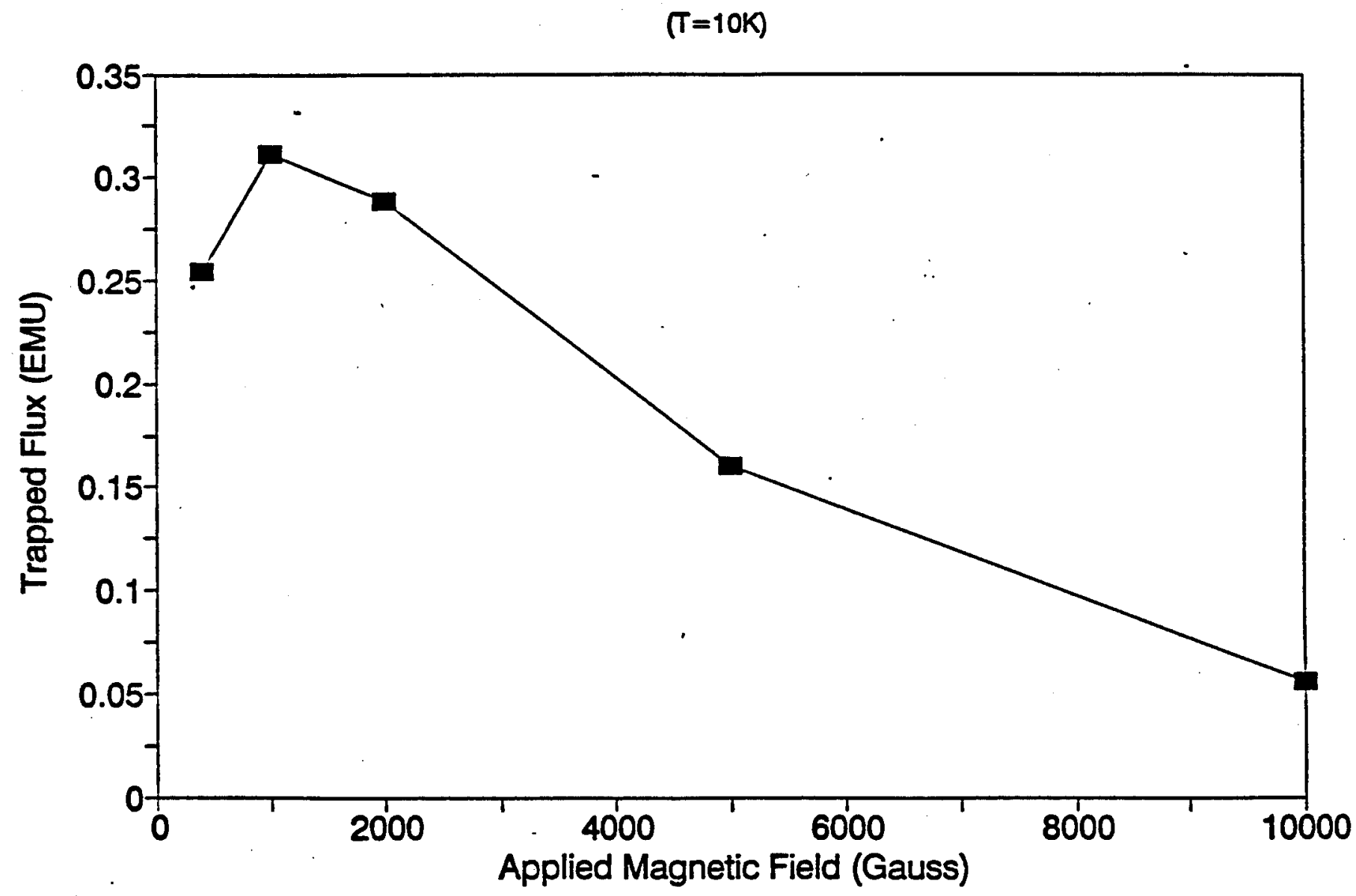

Figure 8. Trapped flux vs applied magnetic field for Ag-coated Bi2212 thick-film Ag-foil sandwich. Sample 7/2/93A. $\mathrm{T}=10 \mathrm{R}$. 
For $\mathrm{Bi}_{1.8} \mathrm{~Pb}_{0.4} \mathrm{Ca}_{2} \mathrm{Sr}_{2} \mathrm{Cu}_{3} \mathrm{O}_{2}, \mathrm{Ag}$-coating did not degenerate $\mathrm{Tc}$ of the powder as revealed by magnetic susceptibility measurements.

For Ag-coated BiPb2223, thick-film, Ag-foil, sandwich-magnets, the optimum processing/annealing temperature is extremely critical. For uncoated BiPb2223 powders, the optimum processing/annealing temperature was $845 \mathrm{C}$, but this is too hot for the $\mathrm{Ag}-$ coated powder since it lowers Tc below 108K. A processing/annealing temperature of $840 \mathrm{C}$ maintains Tc at $108 \mathrm{~K}$. The critical current for our best $\mathrm{Ag}$-coated BiPb2223 thick-film sandwich (sample 8/4/93A) (Figure 9) is $-29 \%$ lower than the uncoated material. Thus, we did not obtain any improvement in Jc with Ag-coating. Again, the trapped flux peaked $\sim 1,000 \mathrm{G}$ which limits performance to this range.

For BiPb2223 Ag-foil constructions, a wide range of Ag-filmthicknesses and sintering temperatures were examined (Table 4) for two different particle sizes ( $\sim \mathrm{um}$ and $\sim 15 \mathrm{um})$ and measured (Table 5) with no improvement in Jc as shown in Figure 10. Clear18 the larger particle size ( $15 \mathrm{um})$ gives superior performance in these experiments. From the literature, it is clear that related techniques of adding $\mathrm{Ag}$ powder to the Hi-Tc powder before fabrication greatly increases ductility and strain tolerance which is very beneficial for Superconix wire/tape projects. 


\section{Jc vs $\mathrm{H}$ \\ $\operatorname{BiPb} 2223(\mathrm{~T}=10 \mathrm{~K})$}

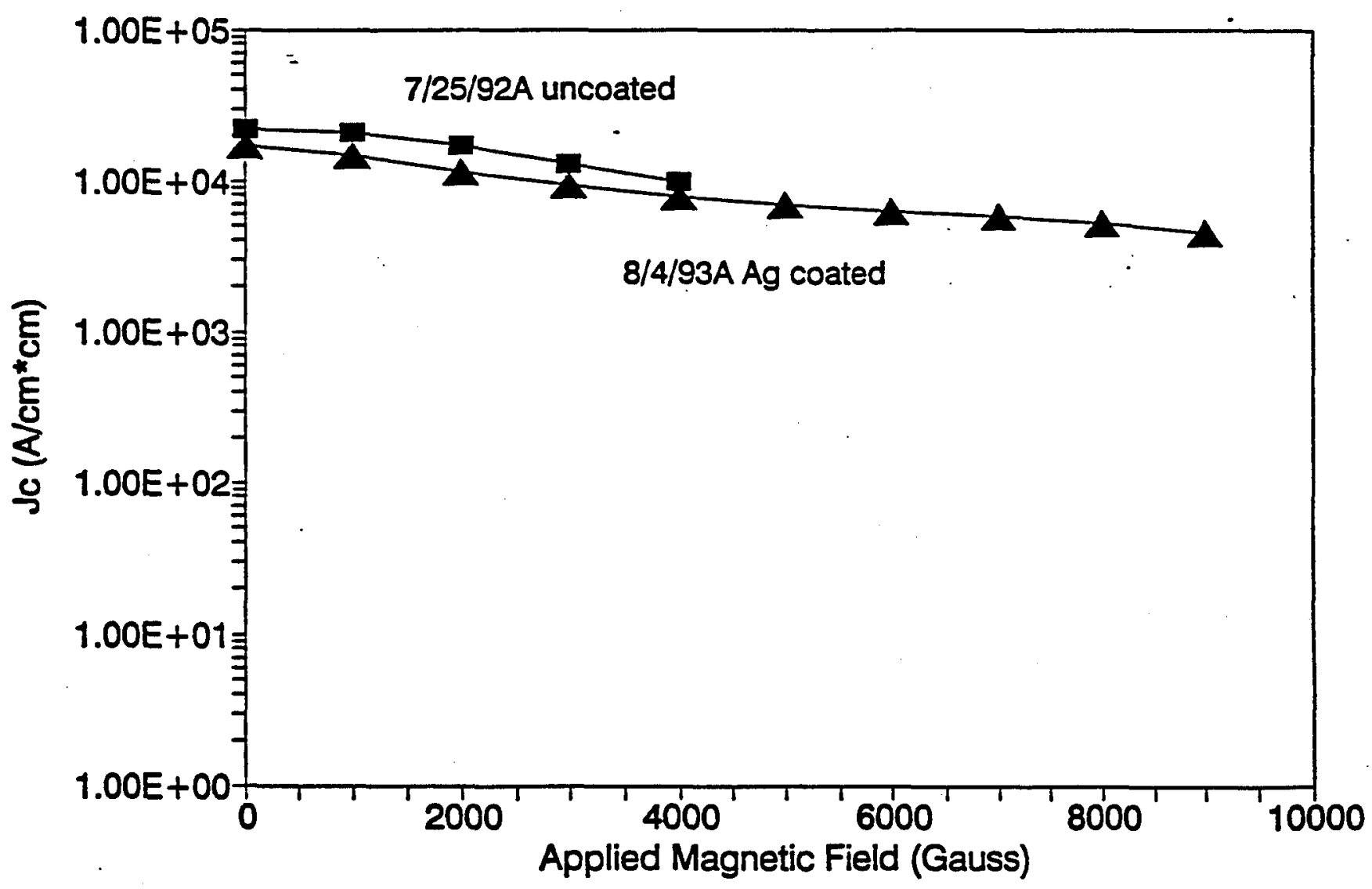

Figure 9. Critical current density (Jc) vs magnetic fleld for uncoated and Ag-coated B1Pb2223 thick-film Ag-foil sandwich. Oncoated sample $7 / 25 / 92 A$. Ag-coated sample B/4/93A. $T=10 \mathrm{~K}$. 


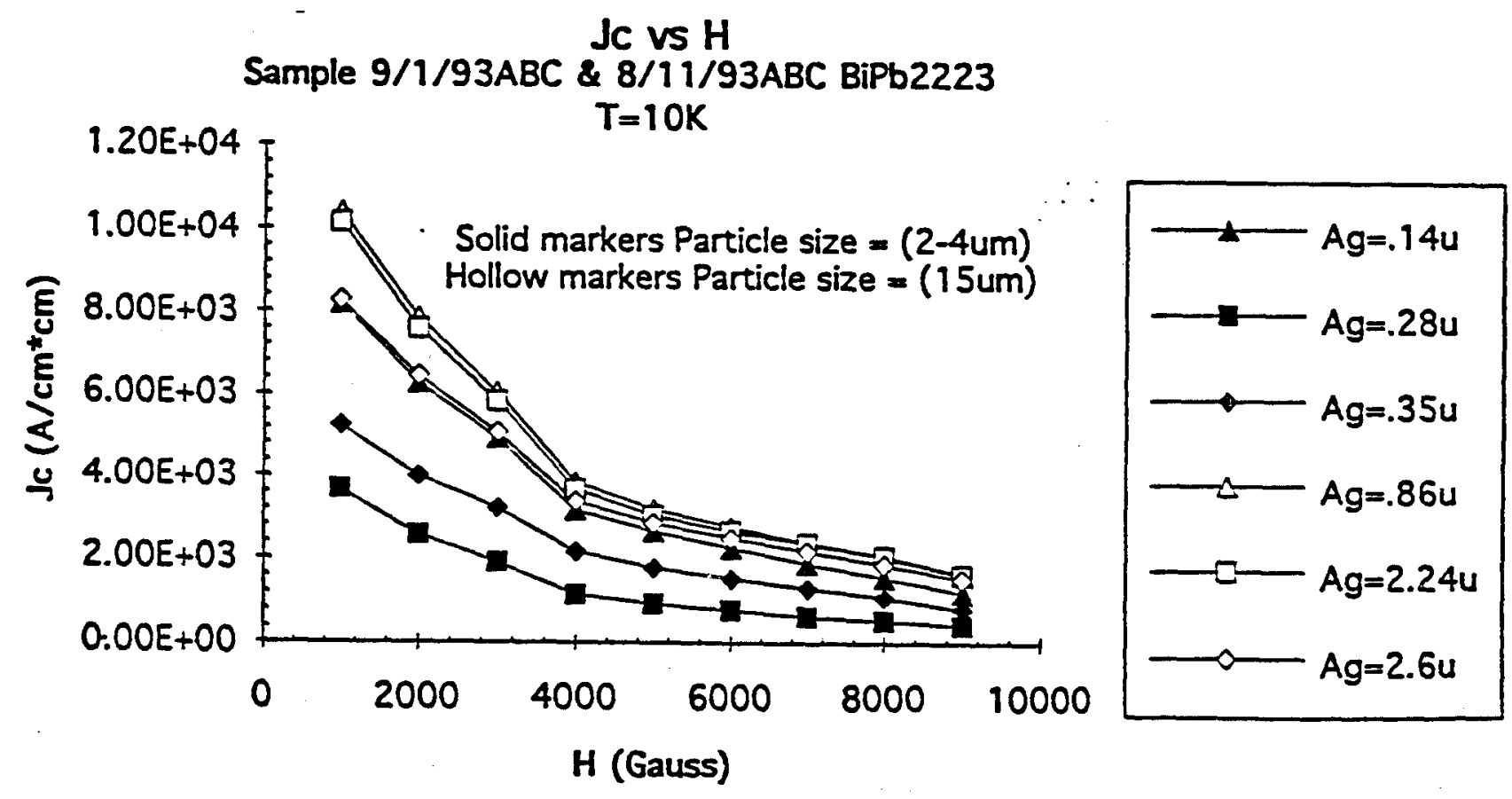

Figure 10. Critical current density (Jc) vs magnetic field for various thicknesses of Ag-coated BiPb2223 powder of two different particle sizes ( $\sim 3 \mathrm{um} \& 15 \mathrm{um})$ fabricated into thick-film Ag-foll sandwiches. $T=10 \mathrm{~K}$. 
LON TC $=$ COATED BiPb2223 Hi-TC SUPERCONDUCTORS

Since $\mathrm{Ag}$-coating the BiPb2223 powder only led to comparable Jc, emphasis was switched to metal-coatings ( $\mathrm{Nb}, \mathrm{Pb}, \mathrm{NbN})$ that are themselves superconducting at low temperatures. The conceived improvement follows. The Bi-Tc cuprate superconductors have very short coherence lengths $10 \mathrm{~A}-20 \mathrm{~A}$ which causes detrimental weaklink problems at the grain boundaries. However, classical metal superconductors ( $\mathrm{Nb}, \mathrm{Pb}, \mathrm{NbN}$ ) have very long coherence lengths $\sim 2,000 \mathrm{~A}$. Thus, if the Bi-Tc grain boundaries are filled with Low Te metals, strong superconducting links should be created at low temperatures. At the higher temperatures, proximity-effect superconductivity may be introduced into the metallic grain boundaries by the Hi-Tc superconductors.

\section{Nb-COATED BiPb2223 Hi-TC SUPERCONDUCTORS}

The BiPb2223 Bi-Tc powders that were $\mathrm{Nb}$-coated by cathodic arc deposition are described in Table 1 . The Nb-coating processes did NOT degrade the BiPb2223 powder as revealed by magnetic susceptibility measurements of the superconducting transition temperature (TC) of the powders (Table 2). However, only sporadic evidence (Tables $3 \& 5$ ) of superconducting $\mathrm{Nb}(\mathrm{TC}=9.2 \mathrm{~K}$ ) was observed but usually $\sim 4.5 \mathrm{~K}$ (not $9.2 \mathrm{~K}$ as expected). This is consistent with the fact that the Tc of superconducting Nb films varies with the substrate conditions which are rough and uncontrolled in our case. The use a voltage-bias during cathodic-arc sputtering gave inconclusive $\mathrm{Nb}$-Tc results.

From the $\mathrm{Nb}$-coated BiPb2223 powders, pressed/sintered thick-film Ag-foil-sandwiches have been made (Table 4) and measured (Table 5). These $\mathrm{Nb}$-coated sandwiches (Table 4) were annealed in various oxygen partial pressures (1x, 10x, 20\%). Annealing in air ( $\sim 20 \%$ $\mathrm{O}_{2}$ ) gave the best results. Although $10 \% \mathrm{O}_{2}$ was not much worse, $1 \%$ $\mathrm{O}_{2}$ was terrible. 
For some Mb-coated BiPb2223 pressed/sintered thick-film Ag-foilsandwiches, the Tc data clearly shows the desired BiPb2223 Tc at 108K and an additional Mb Tc at $\sim 9 \mathrm{~K}$ (Fig 11). Overall, however, the $\mathrm{Nb} \mathrm{Tc}$ is not well controlled or reproduced.

From magnetic hysteresis data (Table 5) on the Nb-coated, pressed/sintered, thick-film, Ag-foil-sandwiches (Table 4), the critical current density $(\mathrm{Jc})$ was calculated from the Bean model via Eq 1. For a sample of BiPb2223, Jc is shown in Figure 12 at $5 \mathrm{~K}, 10 \mathrm{~K}$ and $40 \mathrm{~K}$. Although improvements in Jc (Fig 12) and trapped flux (Fig 13) were obtained at $5 \mathrm{~K}$ where the $\mathrm{Nb}$ is also superconducting, the results are not spectacular as desired. The trapped flux measurements peak at $\sim 1,000$ which limits the magnet performance. Even when superconducting, Nb did not spectacularly improve Jc or trapped flux.

\section{Ag+Nb-COATED BiPb2223 Bi-Tc SUPERCONDUCTORS}

In Tables 1-5, experiments were made by coating BiPb2223 powder with a combination of silver ( $\mathrm{Ag}$ ) then Niobium (Nb). The results were very similar to those of $\mathrm{Nb}$ alone as described above. 


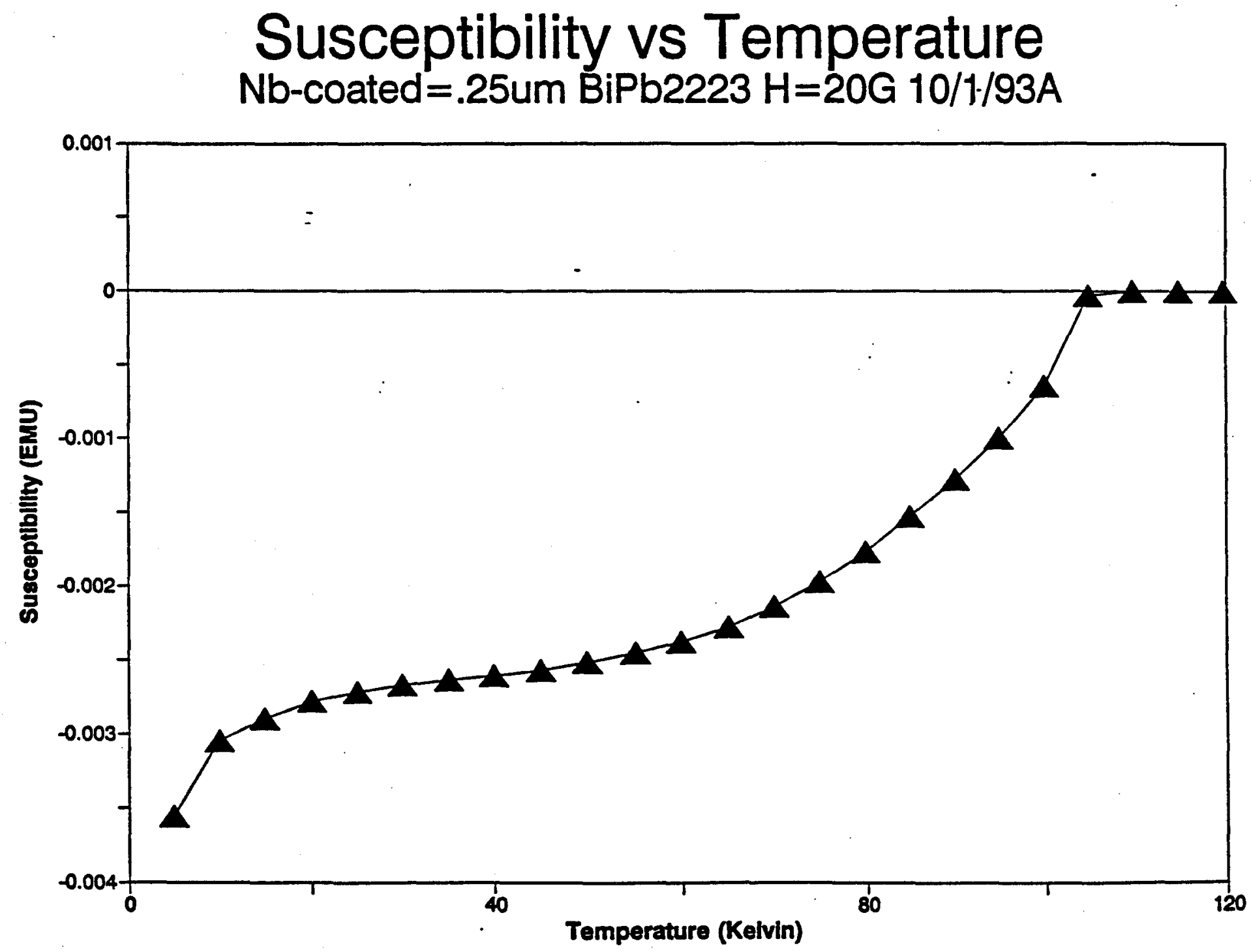

Figure 11. Magnetic susceptibility vs temperature for Nb-coated BiPb2223 thick-film Ag-foil sandwich. Sample 10/1/93A. Note the BiPb2223 $\mathrm{TC}=108 \mathrm{~K}$ and the $\mathrm{Nb} T \mathrm{TC}=\stackrel{\sim \mathrm{R}}{ }$. 


\section{Jc vs H \\ $\mathrm{Nb}$-coated $=.25 \mathrm{um} \mathrm{BiPb2223,} \mathrm{10/1/93A}$}

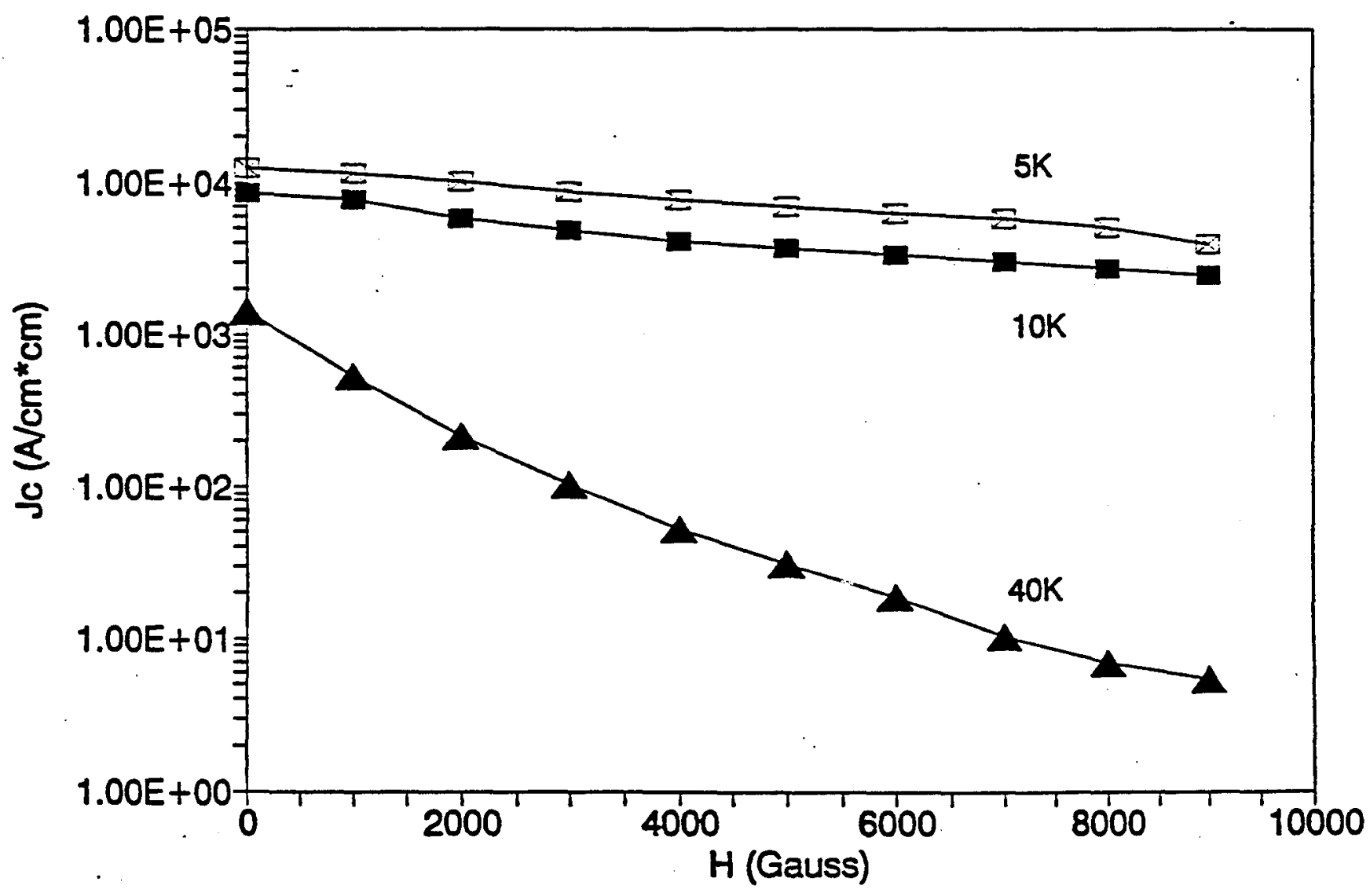

Figure 12. Critical current density (Jc) vs magnetic field for Nb-coated BiPb2223 thick-film Ag-foil sandwich.

Sample 10/1/93A. $T=5 \mathrm{~K}, 10 \mathrm{~K}, \& 40 \mathrm{~K}$. 


\section{Trapped Flux vs Applied Field $\mathrm{Nb}$-coated=.25um BiPb2223, 10/1/93A .}

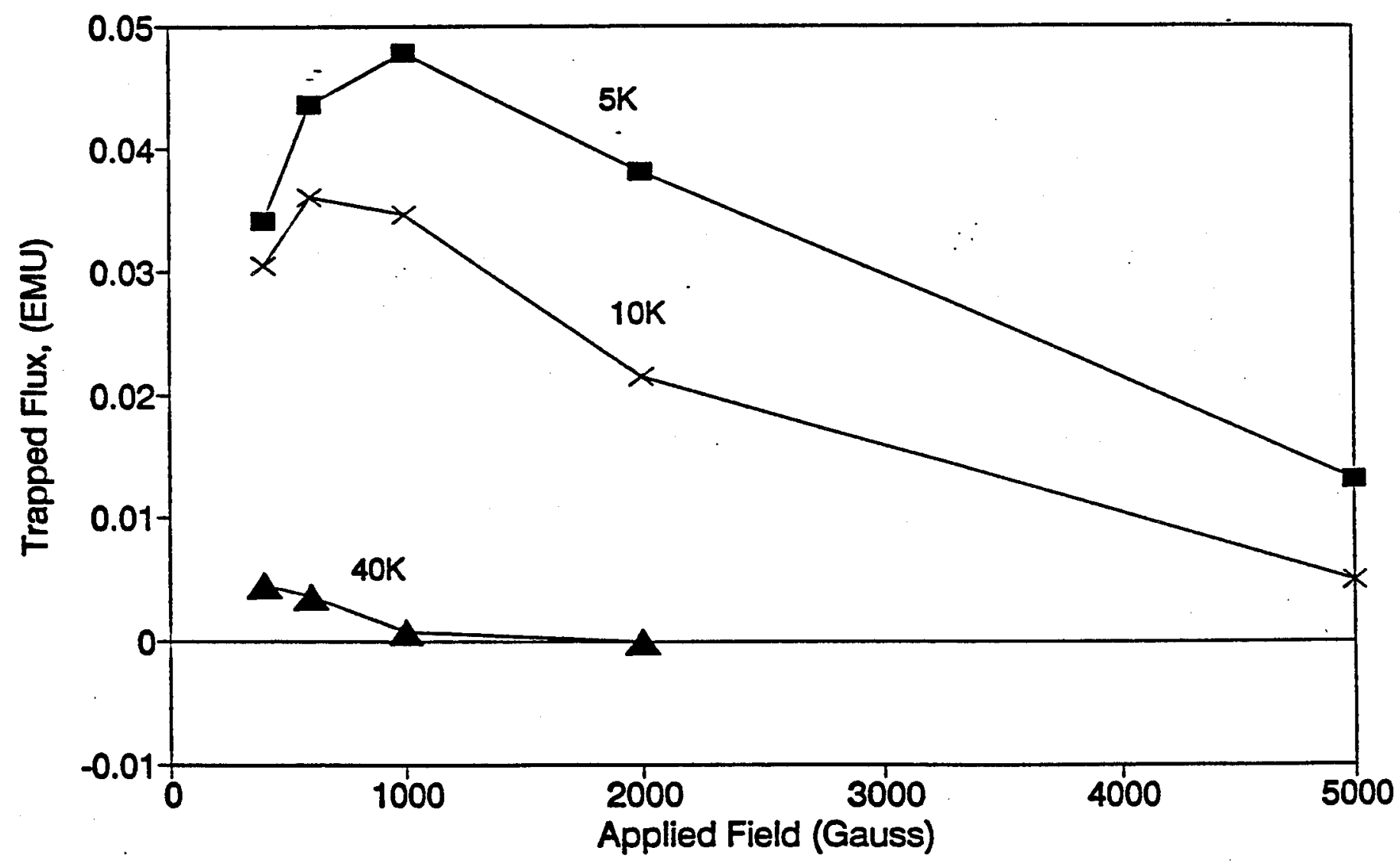

Figure 13. Trapped flux vs applied magnetic field for Nb-coated BiPb2223 thick-film Ag-foil sandwich. Sample 10/1/93A. $T=5 \mathrm{~K}, 10 \mathrm{~K} \& 40 \mathrm{~K}$. 


\section{Pb-COATED BiPb2223 Hi-Tc SUPERCONDUCTORS}

The $\mathrm{Bi}-\mathrm{Tc} \mathrm{Pb}$-coated powders, magnet-sandwich constructions, and their measurements are described in Table $1,2,4 \& 5$.

Onder some sputtering conditions, the $\mathrm{Pb}$-coating process chemically degraded the BiPb2223 powder ( $\mathrm{Tc}=108 \mathrm{~K}$ ) to the Bi2212 (Tc $\sim 80 \mathrm{~K}$ ) phase as evidenced from Tc magnetic susceptibility measurements (Table 2). However, with low sputtering power for $\mathrm{Pb}$-coating, $\mathrm{Tc}=108 \mathrm{~K}$ was maintained while the $\mathrm{Pb}$ superconductivity was dramatically evidenced at $7.2 \mathrm{~K}$ in Figure 14. These low-power $\mathrm{Pb}$ results on powders appeared promising.

When $\mathrm{Pb}$-coated BiPb2223 ( $\mathrm{Tc}=108 \mathrm{~K}$ ) superconducting powder was sintered at sufficiently high temperatures to form sturdy Bi-Jc Ag-foil, thick-film sandwiches, chemical transformation (degradtion) to the Bi2212 ( $\mathrm{Tc}=80 \mathrm{~K}$ ) phase occurred under all other variables including $\mathrm{Pb}$ thickness and particle size (3um \& 15um). As shown in Figure 15, no improvements in Jc or trapped flux were obtained even at $5 \mathrm{~K}$ where our $\mathrm{Pb}$ is erratically superconducting ( $\mathrm{Tc}=7.2 \mathrm{~K}$ ).

\section{NDN LO-TC SUPERCONDUCTOR}

Attempts were made to produce $\mathrm{Nb}_{\mathbf{x}} \mathrm{N}_{\mathrm{y}}$ superconductor ( $\mathrm{Tc}=6 \mathrm{~K}$ to 16K) by sputtering (from a Nb powder target) and by cathodic arc deposition (from a solid Mb target). Preliminary results ( Table 3) on substrates (glass \& aluminum) gave some superconducting Tc's $={ }^{\circ} 5 \mathrm{~K}$, but insufficient time prevented further pursuit. 


\section{Susceptibility of BiPb2223 Powders $\mathrm{Pb}$-coated(9/24/93B), Uncoated(9/24/93A) .}

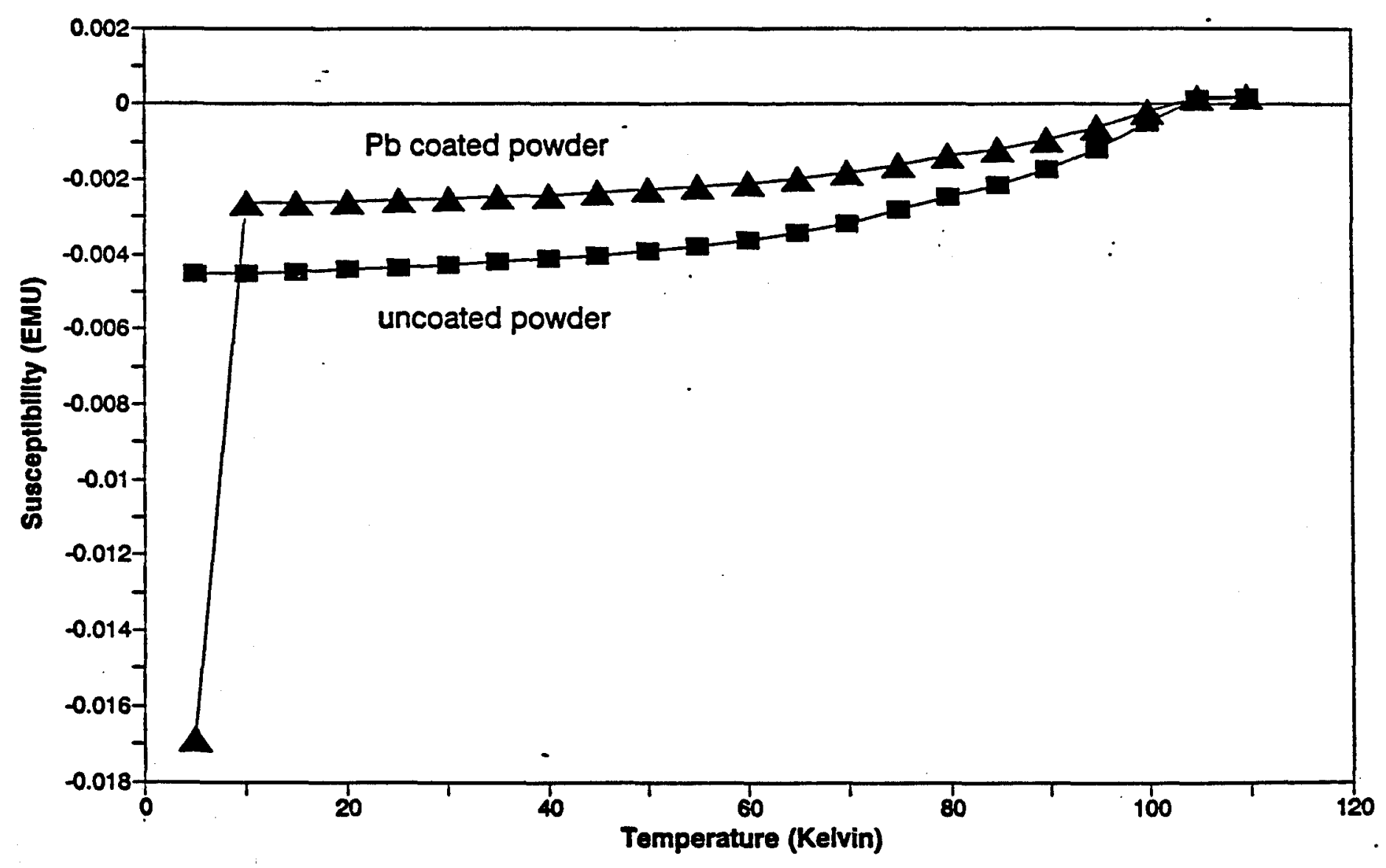

Figure 14. Magnetic susceptibility vs temperature for uncoated and $\mathrm{Pb}$-coated BiPb2223 powder. Uncoated sample 9/24/93A. Pb-Coated Sample 9/24/93B. Note the BiPb2223 $\mathrm{TC}=108 \mathrm{~K}$ and the $\mathrm{Pb} \mathrm{TC}=-7 \mathrm{~K}$. 


\section{$\mathrm{Jc}$ vs $\mathrm{H}$ \\ $\mathrm{Pb}$-coated $=.0247 \mathrm{um} \mathrm{BiPb2223,9/13/93B}$}

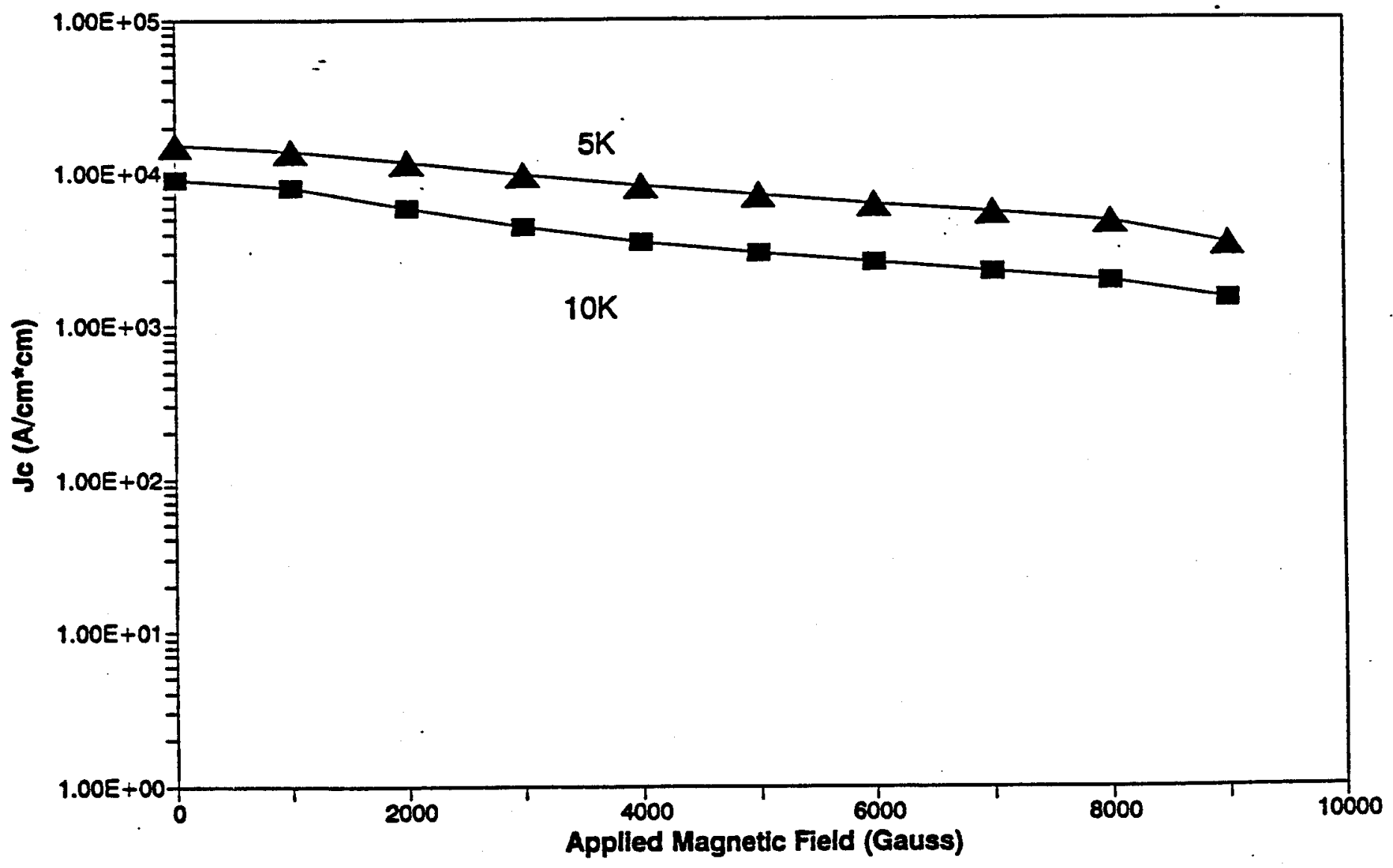

Figure 15. Critical current density (Jc) vs magnetic field for $\mathrm{Pb}$-cóated Bipb2223 thick-film Ag-foil sandwich.

Sample 9/13/93B. $T=5 R \& 10 R$. 


\section{CONCLUSIONS/RECOMENDATIONS}

The overall objective was to produce pre-formed thick-film Bi-Tc superconducting magnets with improved critical current for magnetic refrigerators. To achieve this objective, the Bi-Tc superconducting powder was coated with a thin film of beneficial metal ( $\mathrm{s}$ ) ( $\mathrm{Ag}, \mathrm{Pb}, \mathrm{Nb}$ ) before fabrication into pre-formed thickfilm magnets. The anticipated metallic bonding between the Hi-Tc superconducting grains did NOT dramatically overcome the usual "weak-links" that limit the superconducting current. Even Lead and Niobium, which are superconducting with long coherence lengths at low temperatures, did NOT yield improvements. More specifically, regarding improvements in $\mathrm{Jc}$ of $\mathrm{Bi}_{2} \mathrm{Sr}_{2} \mathrm{CaCu}_{2} \mathrm{O}_{x}$ thick films, Ag-coating gave improvements of $+131 x$. However, for $\mathrm{Bi}_{1.8} \mathrm{~Pb}_{.4} \mathrm{Sr}_{2} \mathrm{Ca}_{2} \mathrm{Cu}_{3} \mathrm{O}_{\mathrm{x}}$ thick-films, Ag-coating decreased Jc $-29 \%$, $\mathrm{Nb}$-coating decreased $\mathrm{Jc} \sim-48 x$, Ag+Nb-coating decreased Jc $-52 \%$, and $\mathrm{Pb}$-coating chemically deteriorated the BiPb2223 superconductor. The improvements in Jc are too marginal for further pursuit in a Phase 2 project at this time, but further efforts with other materials is justified on an exploratory basis in future Phase 1 efforts.

The Ag-coating undoubtedly improved the ductility and strain tolerance of the magnet fabrications and will be useful in another SuperconiX/Plastronics Bi-Tc superconducting wire fabrication project (NSF/SBIR Phase 2 sub-contract).

Finally, SuperconiX just completed another SDIO/SBIR contract on the use of $\mathrm{Hi}$-TC superconductors as the "magneto-caloric" medium in magnetic refrigerators (instead of the usual para/ferromagnetic materials). Very high ( $100 \%)$ magneto-caloric temperature ratios have been obtained at low temperatures ( $<10 \mathrm{~K})$ which may extend the useful range of magnetic refrigerators. However, efficient refrigerator operation at higher temperatures (>20K) appear untenable. 
Table 1. Tabular description of Hi-Tc superconducting powders coated with thin film of different metals ( $\mathrm{Ag}, \mathrm{Nb}, \mathrm{Pb}$ ).

\begin{tabular}{|c|c|c|c|c|c|}
\hline $\begin{array}{l}\text { COATING } \\
\text { CODE }\end{array}$ & $\begin{array}{l}\text { Hi-Tc } \\
\text { POWDER }\end{array}$ & MANUFACTURER & $\begin{array}{c}\text { PARTICLE } \\
\text { SIZE }\end{array}$ & $\begin{array}{l}\text { COATING } \\
\text { MATERIAL }\end{array}$ & $\begin{array}{l}\text { COATING } \\
\text { IBICKNESS }\end{array}$ \\
\hline $\begin{array}{l}\text { B062293A } \\
\text { B062993A }\end{array}$ & $\begin{array}{l}\text { Y123 } \\
\text { Y123 }\end{array}$ & $\begin{array}{l}\text { SSC } \\
\text { SSC }\end{array}$ & $\begin{array}{l}2-6 u m \\
2-6 u m\end{array}$ & $\begin{array}{l}\mathrm{Ag} \\
\mathrm{Ag}\end{array}$ & \\
\hline B063093A & Bi2212 & Celanese & 20um & $\mathbf{A g}$ & \\
\hline $\begin{array}{l}\text { BO71993A } \\
\text { B081193A } \\
\text { B081193B } \\
\text { B083193A } \\
\text { B083193B } \\
\text { B083193C }\end{array}$ & $\begin{array}{l}\text { BiPb2223 } \\
\text { BiPb2223 } \\
\text { BiPb2223 } \\
\text { BiPb2223 } \\
\text { BiPb2223 } \\
\text { BiPb2223 }\end{array}$ & $\begin{array}{l}\text { Celanese } \\
\text { Celanese } \\
\text { Celanese } \\
\text { Celanese } \\
\text { Celanese } \\
\text { Celanese }\end{array}$ & $\begin{array}{l}15 u m \\
15 u m \\
15 u m \\
2-4 u m \\
2-4 u m \\
2-4 u m\end{array}$ & $\begin{array}{l}\mathrm{Ag} \\
\mathrm{Ag} \\
\mathrm{Ag} \\
\mathrm{Ag} \\
\mathrm{Ag} \\
\mathrm{Ag}\end{array}$ & $\begin{array}{r}2.24 u \\
.86 u \\
2.60 u \\
.14 u \\
.28 u \\
.35 u\end{array}$ \\
\hline $\begin{array}{l}\text { B091393B } \\
\text { B091393C } \\
\text { B091393D } \\
\text { B091493A } \\
\text { B091593A } \\
\text { B091593B } \\
\text { B092393A }\end{array}$ & $\begin{array}{l}\text { BiPb2223 } \\
\text { BiPb2223 } \\
\text { BiPb2223 } \\
\text { BiPb2223 } \\
\text { BiPb2223 } \\
\text { BiPb2223 } \\
\text { BiPb2223 }\end{array}$ & $\begin{array}{l}\text { Celanese } \\
\text { Celanese } \\
\text { Celanese } \\
\text { Celanese } \\
\text { Celanese } \\
\text { Celanese } \\
\text { Celanese }\end{array}$ & $\begin{array}{l}15 u m \\
15 u m \\
15 u m \\
2-4 u m \\
2-4 u m \\
2-4 u m \\
2-4 u m\end{array}$ & $\begin{array}{l}\mathrm{Pb} \\
\mathrm{Pb} \\
\mathrm{Pb} \\
\mathrm{Pb} \\
\mathrm{Pb} \\
\mathrm{Pb} \\
\mathrm{Pb}(\text { Lo-P) }\end{array}$ & $\begin{array}{l}.0247 u \\
.0486 u \\
.0670 u \\
.3274 u \\
.4015 u \\
.5003 u \\
.0315 u\end{array}$ \\
\hline $\begin{array}{l}\text { B093093BC } \\
\text { B100693A } \\
\text { B100693B } \\
\text { B101493B }\end{array}$ & $\begin{array}{l}\text { BiPb2223 } \\
\text { BiPb2223 } \\
\text { BiPb2223 } \\
\text { BiPb2223 }\end{array}$ & $\begin{array}{l}\text { Celanese } \\
\text { Celanese } \\
\text { Celanese } \\
\text { Celanese }\end{array}$ & $\begin{array}{l}15 \mathrm{um} \\
15 \mathrm{um} \\
15 \mathrm{um} \\
15 \mathrm{um}\end{array}$ & $\begin{array}{l}\text { Nb } \\
\text { Nb } \\
\text { Nb } \\
\text { Nb ( } 300 \nabla\end{array}$ & $\begin{array}{l}.25 u \\
.4166 u \\
.5833 u \\
.20 u\end{array}$ \\
\hline B102193A & iPb2223 & Celanese & $15 u m$ & $\begin{array}{l}\mathrm{Ag} \\
\mathrm{Nb}(300 \mathrm{~V}\end{array}$ & $\begin{array}{l}.28 u \\
.30 u\end{array}$ \\
\hline
\end{tabular}

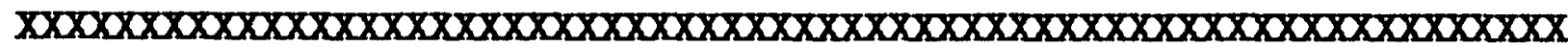


Table 2. Tabular description of measurements on Hi-Tc superconducting powders (coated \& uncoated).

SAMPLE MANUFACTURER. COATING COATING/ FORM MEASUREMENT . CODE PARTICLE SIZE CODE THICKNESS.

8/3/93B Celanese None Oncoated Powder Tc=108K BiPb2223 15um

8/3/93A Celanese BiPb2223 $15 u m$

9/21/93A Celanese BiPb2223 2-4um

9/24/93A Celanese BiPb2223 2-4um

9/24/93B Celanese BiPb2223 2-4um

9/30/93A Celanese BiPb2223 15um

10/06/93B Celanese BiPb2223 15um

10/14/93B Celanese BiPb2223 15um

10/21/93A Celanese BiPb2223 15 um B071993A Ag=2.24u Powder $\begin{gathered}\text { Pom } \\ \text { Tc }=108 \mathrm{~K}\end{gathered}$ B091593B $\mathrm{Pb}=.5003 \mathrm{u}$ Powder $\mathrm{Tc}=88 \mathrm{~K}$ 2-4um

None Uncoated Powder Tc=105K 2-4um

B092393A $\mathrm{Pb}=.0315 \mathrm{u}$ Powder $\mathrm{Tc}=105 \mathrm{~K}$ (low power) 2-4um

$\mathrm{B} 093093 \mathrm{BC} \mathrm{Nb}=.25 \mathrm{u} \quad$ Powder $\mathrm{Tc}=108 \mathrm{~K}$ 15 um

B100693B Nb=.5833u Powder $T c=108 \mathrm{~K}$ 15um

B101493B Nb=.20u Powder Tc=108K Bias 300V 15um

B102193A Ag=.28u Powder $\mathrm{Tc}=105 \mathrm{k}$ $\mathrm{Nb}=.30 \mathrm{u} \quad 15 \mathrm{um}$ Bias 3007

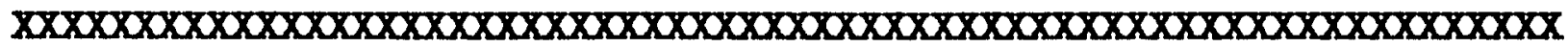


Table 3. Tabular description of measurements on substrates coated with superconducting ( $\mathrm{Nb} \& \mathrm{NbN}$ ) films.

\begin{tabular}{|c|c|c|c|}
\hline $\begin{array}{l}\text { COATING } \\
\text { CODE }\end{array}$ & $\begin{array}{c}\text { COATING/ } \\
\text { THICKNESS. }\end{array}$ & $\begin{array}{l}\text { SUBSTRATE/ } \\
\text { DESCRIPTION }\end{array}$ & MEASUREMEI \\
\hline B-100693-A\&B & $\mathrm{Nb}=.58 \mathrm{um}$ & glass & $\mathrm{Tc}=0 \mathrm{~K}$ \\
\hline $\begin{array}{l}B-101493-B \\
+B-102093-A\end{array}$ & $\mathrm{Nb}=.60 \mathrm{um}$ & glass & $\mathrm{Tc}=4 \mathrm{~K}$ \\
\hline$B-102193-A$ & $\begin{array}{l}\mathrm{Ag}=.28 \mathrm{um} \\
\mathrm{Mb}=.30 \mathrm{um}\end{array}$ & glass & $\mathrm{Tc}=4.5 \mathrm{~K}$ \\
\hline$B-102893-A$ & $\begin{array}{l}\mathrm{NbN}_{\mathrm{X}} \\
\mathrm{N}_{2}=25 \mathrm{~m} \text { Torr }\end{array}$ & glass & Tc=0 $\dot{\mathrm{K}}$ \\
\hline B-102893-B & $\begin{array}{l}\mathrm{NbN}_{\mathbf{x}} \\
\mathrm{N}_{2}=4 \mathrm{mTorr}\end{array}$ & glass & $\mathrm{Tc}=4.5 \mathrm{~K}$ \\
\hline$B-102893-X A$ & $\begin{array}{l}\mathrm{NbN}_{\mathbf{x}} \\
\mathrm{N2} \text { cumulative. }\end{array}$ & $\begin{array}{l}\text { Al foil. } \\
\text { Dark blue, } \\
\text { shiny. }\end{array}$ & $\mathrm{Tc}=0 \mathrm{~K}$ \\
\hline$B-102893-X B$ & $\begin{array}{l}\mathrm{NbN}_{\mathrm{x}} \\
\mathrm{N2} \text { cumulative. }\end{array}$ & $\begin{array}{l}\text { Al foil. } \\
\text { Dark blue, } \\
\text { dull. }\end{array}$ & $\mathrm{Tc}=5 \mathrm{~K}$ \\
\hline B-111593-B & $\begin{array}{l}\mathrm{NbN} \\
\mathrm{N} 2=3 \mathrm{~m} \text { Torr } \\
\mathrm{Ar}=7 \mathrm{~m} \text { Torr }\end{array}$ & $\begin{array}{l}\text { glass. } \\
\text { yellow-green }\end{array}$ & $\mathrm{Tc}=0 \mathrm{~K}$ \\
\hline
\end{tabular}


Table 4. Tabular description of the preparation of Bi-Tc superconducting thick-film Ag-foil sandwich samples (thick-film pre-formed magnets).

\begin{tabular}{|c|c|c|c|c|c|c|}
\hline $\begin{array}{l}\text { SAMPLE } \\
\text { CODE }\end{array}$ & $\begin{array}{l}\text { MANUFACTURER } \\
\text { PARTICLE SIZE }\end{array}$ & $\begin{array}{l}\text { COATING } \\
\text { CODE }\end{array}$ & $\begin{array}{l}\text { COATING } \\
\text { MATERIAL/ } \\
\text { THICKNESS }\end{array}$ & $\begin{array}{l}\text { MAX } \\
\text { TEMP } \\
\text { (C) }\end{array}$ & $\begin{array}{l}\text { ANNEAL } \\
\text { TEMP } \\
\text { (C) }\end{array}$ & $\begin{array}{l}\text { ANNEAL } \\
\text { GAS }\end{array}$ \\
\hline $\begin{array}{l}7 / 2 / 93 \\
\mathrm{Bi} 2212\end{array}$ & $\begin{array}{l}\text { Celanese } \\
\text { zoum }\end{array}$ & B063093A & Ag & 895 & 860 & $\begin{array}{l}100 \% 0 \\
10 \% 0\end{array}$ \\
\hline $\begin{array}{l}7 / 13 / 93 \\
\text { Bi2212 }\end{array}$ & $\begin{array}{c}\text { Celanese } \\
\text { 20um }\end{array}$ & B063093A & Ag & 890 & 860 & $10 \%$ \\
\hline $\begin{array}{l}7 / 26 / 93 \\
\text { BiPb2223 }\end{array}$ & $\begin{array}{c}\text { Celanese } \\
15 \text { un }\end{array}$ & $\begin{array}{l}B 071993 A \\
A g=2.24 u\end{array}$ & $A g=2.24 u$ & 845 & 845 & $\begin{array}{l}1 \% \mathrm{O}_{2} \\
\operatorname{Air}\end{array}$ \\
\hline $\begin{array}{l}7 / 30 / 93 \\
\text { BiPb2223 }\end{array}$ & $\begin{array}{c}\text { Celanese } \\
15 \text { um }\end{array}$ & $\begin{array}{l}B 071993 A \\
A g=2.24 u\end{array}$ & $A_{g}=2.24 u$ & $\begin{array}{l}\text { ?845 } \\
\text { New }\end{array}$ & $\begin{array}{l}? 845 \\
\text { mace }\end{array}$ & $\begin{array}{r}10 \% \\
\text { too ho }\end{array}$ \\
\hline $\begin{array}{l}\text { 8/4/93A } \\
\text { BiPb2223 }\end{array}$ & $\begin{array}{c}\text { Celanese } \\
15 \mathrm{um}\end{array}$ & $\begin{array}{l}B 071993 A \\
A g=2.24 u\end{array}$ & $A g=2.24 u$ & 840 & 840 & $10 x$ \\
\hline $\begin{array}{l}\text { 8/11/93B } \\
\text { BiPb2223 }\end{array}$ & $\begin{array}{c}\text { Celanese } \\
15 \text { um }\end{array}$ & $\begin{array}{l}\mathrm{B} 071993 A \\
\mathrm{Ag}=2.24 \mathrm{u}\end{array}$ & $A g=2.24 u$ & 842.5 & 842.5 & $10 \% c$ \\
\hline $\begin{array}{l}\text { 8/11/93A } \\
\text { BiPb2223 }\end{array}$ & $\begin{array}{c}\text { Celanese } \\
15 \mathrm{um}\end{array}$ & $\begin{array}{l}\mathrm{BO} 81193 \mathrm{~A} \\
\mathrm{Ag}=.86 \mathrm{u}\end{array}$ & $A g=.86 u$ & 842.5 & 842.5 & $10 \%$ \\
\hline $\begin{array}{l}\text { 8/11/93C } \\
\mathrm{BiPb} 2223\end{array}$ & $\begin{array}{c}\text { Celanese } \\
15 \mathrm{um}\end{array}$ & $\begin{array}{l}\mathrm{BO} 81193 \mathrm{~B} \\
\mathrm{Ag}=2.6 \mathrm{u}\end{array}$ & $A g=2.6 u$ & 842.5 & 842.5 & $10 \%$ \\
\hline $\begin{array}{l}\text { 9/1/93A } \\
\text { BiPb2223 }\end{array}$ & $\begin{array}{l}\text { Celanese } \\
\text { 2-4um }\end{array}$ & $\begin{array}{l}B 083193 A \\
A g=.14 u\end{array}$ & $A g=.14 u$ & 842.5 & 842.5 & $10 \% \mathrm{C}$ \\
\hline $\begin{array}{l}9 / 1 / 93 B \\
\text { BiPb2223 }\end{array}$ & $\begin{array}{l}\text { Celanese } \\
\text { 2-4um }\end{array}$ & $\begin{array}{l}\mathrm{BO} 83193 \mathrm{~B} \\
\mathrm{Ag}=.28 \mathrm{u}\end{array}$ & $A g=.28 u$ & 842.5 & 842.5 & $10 \% \mathrm{C}$ \\
\hline $\begin{array}{l}\text { 9/1/93C } \\
\text { BiPb2223 }\end{array}$ & $\begin{array}{c}\text { Celanese } \\
\text { 2-4um }\end{array}$ & $\begin{array}{l}\mathrm{B083193C} \\
\mathrm{Ag}=.35 \mathrm{u}\end{array}$ & $A g=.35 u$ & 842.5 & 842.5 & $10 \%$ \\
\hline $\begin{array}{l}9 / 7 / 93 A \\
\text { BiPb2223 }\end{array}$ & $\begin{array}{l}\text { Celanese } \\
\text { 2-4um }\end{array}$ & $\begin{array}{l}\mathrm{BOB3193A} \\
\mathrm{Ag}=.14\end{array}$ & $A g=.14 u$ & 835 & 835 & $10 \% 0$ \\
\hline $\begin{array}{l}9 / 7 / 93 B \\
\text { BiPb2223 }\end{array}$ & $\begin{array}{c}\text { Celanese } \\
\text { 2-4um }\end{array}$ & $\begin{array}{l}\mathrm{B083193B} \\
\mathrm{Ag}=.28\end{array}$ & $A g=.28 u$ & 835 & 835 & $10 \%$ \\
\hline $\begin{array}{l}9 / 7 / 93 C \\
\text { BiPb2223 }\end{array}$ & $\begin{array}{c}\text { Celanese } \\
\text { 2-4um }\end{array}$ & $\begin{array}{l}\mathrm{B083193C} \\
\mathrm{Ag}=.35\end{array}$ & $A g=.35 u$ & 835 & 835 & $10 \%$ \\
\hline
\end{tabular}


Table 4. Continued.

\begin{tabular}{|c|c|c|c|c|c|c|}
\hline $\begin{array}{c}\text { SAMPLE } \\
\text { CODE }\end{array}$ & $\begin{array}{l}\text { IANUFACTURER } \\
\text { ARTICLE SIZE }\end{array}$ & $\begin{array}{l}\text { COATING } \\
\text { CODE }\end{array}$ & $\begin{array}{l}\text { COATING } \\
\text { MATERIAL/ } \\
\text { TAICKNESS }\end{array}$ & $\begin{array}{l}\text { MAX } \\
\text { TEMP } \\
\text { (C) }\end{array}$ & $\begin{array}{l}\text { ANNEAL } \\
\text { TEMPP } \\
\text { (C) }\end{array}$ & $\begin{array}{l}\text { ANNEAL } \\
\text { GAS }\end{array}$ \\
\hline $\begin{array}{l}9 / 13 / 93 B \\
\text { BiPb223 }\end{array}$ & $\begin{array}{l}\text { Celanese } \\
\text { 15um }\end{array}$ & $\begin{array}{l}\mathrm{B091393B} \\
\mathrm{Pb}=.0247 \mathrm{u}\end{array}$ & $\mathrm{Pb}=.0247 u$ & 825 & 825 & $10 \% \mathrm{O}_{2}$ \\
\hline $\begin{array}{l}9 / 13 / 93 \mathrm{C} \\
\text { BiPb2223 }\end{array}$ & $\begin{array}{l}\text { Celanese } \\
15 u m\end{array}$ & $\begin{array}{l}\mathrm{B091393C} \\
\mathrm{Pb}=.0486 \mathrm{u}\end{array}$ & $\mathrm{Pb}=.0486 \mathrm{u}$ & 825 & 825 & $10 \mathrm{xO}_{2}$ \\
\hline $\begin{array}{l}9 / 13 / 93 \mathrm{D} \\
\text { BiPb2223 }\end{array}$ & $\begin{array}{l}\text { Celanese } \\
15 \text { um }\end{array}$ & $\begin{array}{l}\mathrm{B091393D} \\
\mathrm{Pb}=.0670 \mathrm{u}\end{array}$ & $\mathrm{Pb}=.0670 \mathrm{u}$ & 825 & 825 & $10 \mathrm{KO}_{2}$ \\
\hline $\begin{array}{l}9 / 17 / 93 A \\
\text { BiPb2223 }\end{array}$ & $\begin{array}{l}\text { Celanese } \\
2-4 u m\end{array}$ & $\begin{array}{l}\mathrm{B091493A} \\
\mathrm{Pb}=.3274 \mathrm{u}\end{array}$ & $\mathrm{Pb}=.3274 \mathrm{u}$ & 832 & 832 & $10 \% \mathrm{O}_{2}$ \\
\hline $\begin{array}{l}\text { 9/17/93B } \\
\text { BiPb2223 }\end{array}$ & $\begin{array}{l}\text { Celanese } \\
\text { 2-4um }\end{array}$ & $\begin{array}{l}\mathrm{B091593A} \\
\mathrm{Pb}=.4015 \mathrm{u}\end{array}$ & $\mathrm{Pb}=.4015 \mathrm{u}$ & 832 & 832 & $10 \mathrm{OO}_{2}$ \\
\hline $\begin{array}{l}9 / 17 / 93 \mathrm{C} \\
\text { BiPb2223 }\end{array}$ & $\begin{array}{l}\text { Celanese } \\
\text { 2-4um }\end{array}$ & $\begin{array}{l}\mathrm{B} 091593 \mathrm{~B} \\
\mathrm{~Pb}=.5003 \mathrm{u}\end{array}$ & $\mathrm{Pb}=.5003 \mathrm{u}$ & 832 & 832 & $10 \% \mathrm{O}_{2}$ \\
\hline $\begin{array}{l}9 / 22 / 93 \mathrm{~A} \\
\mathrm{BiPb} 2223\end{array}$ & $\begin{array}{l}\text { Celanese } \\
\text { 2-4um }\end{array}$ & $\begin{array}{l}\mathrm{B091493A} \\
\mathrm{Pb}=.3274 \mathrm{u}\end{array}$ & $\mathrm{Pb}=.3274 \mathrm{u}$ & 500 & 500 & $10 \mathrm{O}_{2}$ \\
\hline $\begin{array}{l}9 / 22 / 93 B \\
\text { BiPb2223 }\end{array}$ & $\begin{array}{c}\text { Celanese } \\
\text { 2-4um }\end{array}$ & $\begin{array}{l}\mathrm{B091493A} \\
\mathrm{Pb}=.3274 \mathrm{u}\end{array}$ & $\mathrm{Pb}=.3274 \mathrm{u}$ & 650 & 650 & $10 \% \mathrm{O}_{2}$ \\
\hline $\begin{array}{l}9 / 22 / 93 \mathrm{C} \\
\text { BiPb2223 }\end{array}$ & $\begin{array}{l}\text { Celanese } \\
\text { 2-4um }\end{array}$ & $\begin{array}{l}\mathrm{B091493A} \\
\mathrm{Pb}=.3274 \mathrm{u}\end{array}$ & $\mathrm{Pb}=.3274 \mathrm{u}$ & 800 & 800 & $10 \% \mathrm{O}_{2}$ \\
\hline $\begin{array}{l}9 / 29 / 93 \mathrm{~A} \\
\text { BiPb2223 }\end{array}$ & $\begin{array}{l}\text { Celanese } \\
\text { 2-4um }\end{array}$ & $\begin{array}{l}\mathrm{B0} 92393 \mathrm{~A} \\
\mathrm{~Pb}=.0315 \mathrm{u}\end{array}$ & $\mathrm{Pb}=.0315 \mathrm{u}$ & 825 & 825 & $10 \% 0$ \\
\hline
\end{tabular}


Table 4. Concluded.

\begin{tabular}{|c|c|c|c|c|c|c|}
\hline $\begin{array}{c}\text { SAMPLE } \\
\text { CODE }\end{array}$ & $\begin{array}{l}\text { ANUFACTURER } \\
\text { ARTICLE SIZE }\end{array}$ & $\begin{array}{c}\text { COATING } \\
\text { CODE }\end{array}$ & $\begin{array}{l}\text { COATING } \\
\text { MATERIAL/ } \\
\text { TEICKANSS }\end{array}$ & $\begin{array}{l}\operatorname{MAX} \\
\text { TEMP } \\
\text { (C) }\end{array}$ & $\begin{array}{l}\text { ANNEAL } \\
\text { TEMP } \\
\text { (C) }\end{array}$ & $\begin{array}{l}\text { ANNEEAL } \\
\text { GAS }\end{array}$ \\
\hline $\begin{array}{l}10 / 1 / 93 A \\
\text { BiPb2223 }\end{array}$ & $\begin{array}{c}\text { Celanese } \\
\text { 15um }\end{array}$ & $\begin{array}{l}\mathrm{B093093BC} \\
\mathrm{Nb}=.25 \mathrm{a}\end{array}$ & $\mathrm{Nb}=.25 \mathrm{u}$ & 840 & 840 & $10 \mathrm{xO}_{2}$ \\
\hline $\begin{array}{l}10 / 7 / 93 A \\
\text { BiPb2223 }\end{array}$ & $\begin{array}{c}\text { Celanese } \\
\text { 15um }\end{array}$ & $\begin{array}{l}\mathrm{B100693A} \\
\mathrm{Nb}=.4166 \mathrm{u}\end{array}$ & $\mathrm{Nb}=.4166 \mathrm{u}$ & 840 & 840 & $1 \mathrm{xO}_{2}$ \\
\hline $\begin{array}{l}10 / 7 / 93 B \\
\text { BiPb2223 }\end{array}$ & $\begin{array}{c}\text { Celanese } \\
\text { 15um }\end{array}$ & $\begin{array}{l}\mathrm{B} 100693 \mathrm{~B} \\
\mathrm{Nb}=.5833 \mathrm{u}\end{array}$ & $\mathrm{Nb}=.5833 \mathrm{u}$ & 840 & 840 & $1 x_{2}$ \\
\hline $\begin{array}{l}10 / 15 / 93 \mathrm{~A} \\
\text { BiPb2223 }\end{array}$ & $\begin{array}{l}\text { Celanese } \\
\text { 15um }\end{array}$ & $\begin{array}{l}\mathrm{B101493B} \\
\mathrm{Nb}=.20 \mathrm{u}\end{array}$ & $\begin{array}{l}\mathrm{Nb}=.20 \mathrm{u} \\
(300 \mathrm{~V})\end{array}$ & 840 & 840 & $1 \times O_{2}$ \\
\hline $\begin{array}{l}10 / 22 / 93 A \\
\text { BiPb2223 }\end{array}$ & $\begin{array}{c}\text { Celanese } \\
15 u m\end{array}$ & $\begin{array}{l}\mathrm{B102193A} \\
\mathrm{Ag}=.28 \mathrm{u} \\
\mathrm{Nb}=.30 \mathrm{u}\end{array}$ & $\begin{array}{l}\mathrm{Ag}=.28 \mathrm{u} \\
\mathrm{Nb}=.30 \mathrm{u} \\
(300 \mathrm{~V})\end{array}$ & 840 & 840 & $10 \mathrm{KO}_{2}$ \\
\hline $\begin{array}{l}10 / 27 / 93 \mathrm{Nt} \\
\text { BiPb2223 }\end{array}$ & $\begin{array}{c}\text { b Celanese } \\
15 u m\end{array}$ & $\begin{array}{l}\mathrm{B093093BC} \\
\mathrm{Nb}=.25 \mathrm{u}\end{array}$ & $\mathrm{Nb}=.25 \mathrm{u}$ & 840 & 840 & $\underset{\left(20 \mathrm{XO}_{2}\right)}{\operatorname{Air}}$ \\
\hline $\begin{array}{l}10 / 27 / 93 \\
\mathrm{Nb}+\mathrm{Ag} \\
\mathrm{BiPb} 223\end{array}$ & $\begin{array}{c}\text { Celanese } \\
15 \text { um }\end{array}$ & $\begin{array}{l}\mathrm{B102193A} \\
\mathrm{Ag}=.28 \mathrm{u} \\
\mathrm{Nb}=.30 \mathrm{u}\end{array}$ & $\begin{array}{l}\mathrm{Ag}=.28 \mathrm{u} \\
\mathrm{Nb}=.30 \mathrm{u} \\
(300 \mathrm{~V})\end{array}$ & 840 & 840 & $\underset{(20 \% 0}{\operatorname{Air}}$ \\
\hline
\end{tabular}


Table 5. Tabular summary of measurements on Bi-Tc superconducting thick-film magnets. The following

$M=$ Magnetic Moment.

abbreviated codes are used.

$T=$ Temperature.

$\dot{t}=$ time.

H = Magnetic Field.

Tc = Superconducting transition temperature.

ZFC = Zero field cooled.

FC = Field cooled.

EW = Field warmed.

\section{SAMPLE MEASUREMENTS}

7/2/93 (ZFC) M vs T (FW $B=20 G$ ) (B perp)

Bi2212 $M$ vs $B$ Hysteresis (B perp) at $T=10 \mathrm{~K}, 40 \mathrm{~K}, 70 \mathrm{~K}$.

Celanese FC Trapped Flux. M vs $t$ (10K, 40K)

Ag=? FC Trapped Flux vs Applied Magnetic Field (10K, 40K)

$7 / 13 / 93$ (ZFC) $M$ vs $T$ (FW $B=20 G$ ) (B perp) ( TC=75K) Bi2212 $M$ vs $B$ Hysteresis ( $B$ perp) at $T=10 \mathrm{~K}, 40 \mathrm{~K}, 70 \mathrm{~K}$.

Celanese FC Trapped FIux. M vs $t$ (10K, 40K)

$\mathrm{Ag}=$ ?

FC Trapped Flux vs Applied Magnetic Field (10K, 40K)

7/26/93A

BiPb2223

Celanese

(ZFC) M vs T (FW $B=20 G$ ) (B perp)

$M$ vs $B$ Bysteresis ( $\mathrm{H}$ perp) at $\mathrm{T}=10 \mathrm{~K}, 40 \mathrm{~K}, 70 \mathrm{~K}$.

FC Trapped Flux. A vs $t$ (10K, 40K)

Ag=2.24u FC Trapped Flux vs Applied Magnetic Field (10K, 40K)

$7 / 26 / 93 B$ (ZFC) $M$ vs $T$ (FW $B=20 G)$ ( $\mathrm{B} \mathrm{perp)} \mathrm{(Tc=65K)}$

BiPb2223

Celanese

$\mathrm{Ag}=2.24 \mathrm{u}$

$7 / 30 / 93$ (ZFC) M Vs T (FW $\mathrm{B}=20 \mathrm{G}$ ) (B perp)

BiPb2223 (New Oncontrolled Furnace Too Bot)

$(\mathrm{Tc}=80 \mathrm{~K})$

Celanese

$\mathrm{Ag}=2.24 \mathrm{u}$

$8 / 3 / 93 \mathrm{~A}$ (ZFC) M vs $T$ ( $F W \quad B=20 G$ )

BiPb2223 - Ag Coated POWDER.

Celanese - $\mathrm{Ag}=2.24 \mathrm{u}$.

$\mathrm{Ag}=2.24 \mathrm{u}$

$8 / 3 / 93 B$ ( $Z F C)$ M VS T ( $F W ~ B=20 G$ )

BiPb2223 - Uncoated POWDER.

Celanese - Uncoated POWDER.

Oncoated

8/4/93A

BiPb2223

Celanese

$\mathrm{Ag}=2.24 \mathrm{u}$
(ZFC) $M$ vs $T$ (EW $B=20 G$ ) ( $B$ perp)

$M$ vs $B$ Hysteresis ( $B$ perp) at $T=10 \mathrm{~K}, 40 \mathrm{~K}, 70 \mathrm{~K}$ )

FC Trapped Flux. M rs $t$ (10K)

FC Trapped Flux vs Applied Magnetic Field (10K) 
Table 5. Continued.

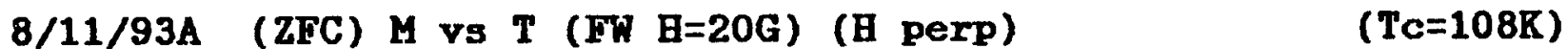

BiPb2223 $M$ vs $B$ Hysteresis (B perp) at ( $T=10 \mathrm{~K}, 40 \mathrm{~K}, 70 \mathrm{~K}$ )

Celanese FC Trapped Flux. M vs $t(10 \mathrm{~K}, 40 \mathrm{~K})$

$\mathrm{Ag}=.86 \mathrm{u}$ FC Trapped Flux vs Applied Magnetic Field (10K,40K)

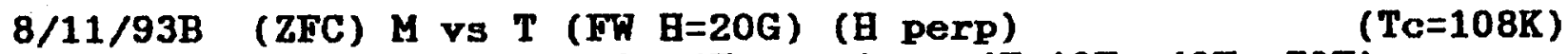

BiPb2223 M vs $B$ Bysteresis ( $B$ perp) at ( $T=10 \mathrm{~K}, 40 \mathrm{~K}, 70 \mathrm{~K}$ )

Celanese FC Trapped Flux. M vs $t(10 \mathrm{~K}, 40 \mathrm{~K})$

$\mathbf{A g}=2.24 \mathrm{u}$ FC Trapped Flux vs Applied Magnetic Field (10K,40K)

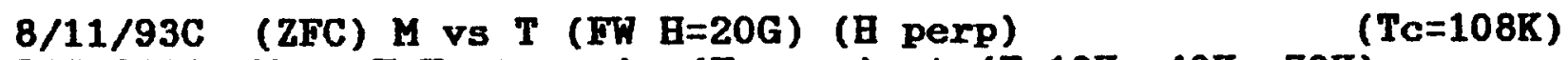

BiPb2223 M vs $B$ Hysteresis ( $B$ perp) at ( $T=10 \mathrm{~K}, 40 \mathrm{~K}, .70 \mathrm{~K}$ )

Celanese FC Trapped Flux. M vs $t$ (10K,40K)

$\mathrm{Ag}=2.6 \mathrm{u}$ FC Trapped Flux vs Applied Magnetic Field (10K,40K)

9/1/93A

(ZFC) M vs T (FW B=20G) ( $\mathrm{B}$ perp)

( $\mathrm{Tc}=108 \mathrm{~K})$

BiPb2223

Celanese

$\mathrm{Ag}=.14 \mathrm{u}$

$M$ vs $B$ Hysteresis ( $B$ perp) at ( $T=10 \mathrm{~K}, 40 \mathrm{~K})$

FC Trapped Flux. M vs $t$ (10K)

FC Trapped Flux vs Applied Magnetic Field (10K)

9/1/93B

BiPb2223

(ZFC) $M$ vs $T$ (FW $B=20 G$ ) (B perp)

$(\mathrm{Tc}=108 \mathrm{~K})$

Celanese FC Trapped Flux. M vs $t$ (10K)

$\mathrm{Ag}=.28 \mathrm{u}$ FC Trapped Flux vs Applied Magnetic Field (10K)

$9 / 1 / 93 \mathrm{C}$

BiPb2223

(ZFC) M vs T (FW $B=20 G$ ) (B perp)

$(\mathrm{Tc}=108 \mathrm{~K})$

Celanese

$\mathrm{Ag}=.35 \mathrm{u}$

$M$ vs $B$ Hysteresis ( $B$ perp) at $(T=10 \mathrm{~K}, 40 \mathrm{~K}$ )

FC Trapped Flux. M vs $t$ (10K)

$9 / 7 / 93 \mathrm{~A}$

BiPb2223

FC Trapped Flux vs Applied Magnetic Field (10K)

Celanese

(ZFC) M vs $T$ (FW $B=20 G$ ) (B perp)

$(\mathrm{Tc}=108 \mathrm{~K})$

$\mathrm{Ag}=.14 \mathrm{u}$

$M$ vs $B$ Hysteresis ( $B$ perp) at ( $T=10 \mathrm{~K}, 40 \mathrm{~K}$ )

FC Trapped Flux. M ys $t$ (10K, 40K)

FC Trapped Flux vs Applied Magnetic Field (10K)

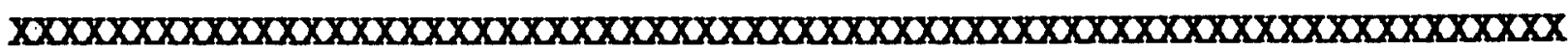

9/13/93B (ZFC) M vs T ( Fw $B=20 G$ ) (B perp)

( $\mathrm{TC}=70 \mathrm{~K}$ )

BiPb2223
Celanese FC Trapped Flux M vs $t$ ( $5 \mathrm{~K}, 10 \mathrm{~K}$ )

$\mathrm{Pb}=.0247 \mathrm{u}$ FC Trapped Flux vs Applied Magnetic Field (5K, 10K)

$9 / 13 / 93 \mathrm{C}$

(ZFC) $M$ vs $T$ (FW $B=20 G$ ) (B perp)

$(\mathrm{Tc}=75 \mathrm{~K})$

BiPb2223

$M$ vs $B$ Bysteresis (B perp) at $(T=10 \mathrm{~K}$ )

Celanese

$\mathrm{Pb}=.0486 \mathrm{u}$

9/17/93C

(ZFC) M vs $T$ (FW $B=20 G$ ) (B perp)

$(\mathrm{Tc}=55 \mathrm{~K})$

BiPb2223

$M$ vs $B$ Hysteresis ( $B$ perp) at $(T=5 K, 10 K)$

Celanese

$\mathrm{Pb}=.5003 \mathrm{u}$ 
Table 5. Continued.

9/21/93A (ZFC) M vs T (FW $\mathrm{B=20G)}$

$(\mathrm{Tc}=88 \mathrm{~K})$

BiPb2223 - $\mathrm{Pb}$ Coated POWDER

Celanese $-\mathrm{Pb}=.5003 u m$

$\mathrm{Pb}=.5003 \mathrm{u}$

$9 / 22 / 93 \mathrm{C}$

(ZFC) $M$ vs $T$ (FW $\mathrm{B}=20 \mathrm{G}$ )

BiPb2223 M vs B Bysteresis ( $B$ perp) at ( $T=5 \mathrm{~K}, 10 \mathrm{~K}, 40 \mathrm{~K}$ )

Celanese FC Trapped Flux. M vs $t$ (5K, 10K, 40K)

$\mathrm{Pb}=.3274 \mathrm{u}$ FC Trapped Flux vs Applied Magnetic Field (5k, 10K, 40K)

9/24/93A (ZFC) M vs T (FW B=20G)

$(\mathrm{Tc}=105 \mathrm{~K})$

BiPb2223 - Oncoated POWDER

Celanese - Oncoated POWDER

Oncoated

$9 / 24 / 93 B$

BiPb2223

Celanese

$\mathrm{Pb}=.0315 \mathrm{u}$

(ZFC) $M$ vs $T$ (FW $B=20 G$ )

$(\mathrm{Tc}=105 \mathrm{~K})$

$-\mathrm{Pb}$ coated POWDER

$-\mathrm{Pb}=.0315 \mathrm{um}$

$9 / 29 / 93 A$

(ZFC) $M$ vs $T$ (FW $B=20 G)$

BiPb2223 $M$ vs $B$ Hysteresis ( $B$ perp) at ( $T=5 R, 10 K)$

$(\mathrm{Tc}=108 \mathrm{~K})$

Celanese

$\mathrm{Pb}=.0315 \mathrm{u}$

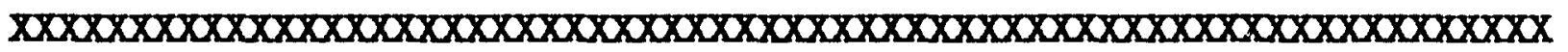

9/30/93A (ZFC) M Vs T (FW B=20G)

( $\mathrm{Tc}=108 \mathrm{~K}$ )

BiPb2223

-Nb coated POWDER

Celanese $-\mathrm{Nb}=.25 \mathrm{um}$

$\mathrm{Nb}=.25 \mathrm{u}$

$10 / 1 / 93 \mathrm{~A}$ ( $\mathrm{FFC}$ ) $\mathrm{M}$ vs $\mathrm{T}$ (FW $\mathrm{B}=20 \mathrm{G}$ )

$(\mathrm{Tc}=108 \mathrm{~K})$

BiPb2223 M vs $B$ Bysteresis (B perp) at ( $T=2 K, 5 K, 10 K, 40 K$ )

Celanese FC Trapped Flux. M vs $t$ (5K, 10K, 40K)

$\mathrm{Nb}=.25 \mathrm{u} \quad$ FC Trapped Flux vs Applied Magnetic Field (5K, 10K, 40K)

$10 / 6 / 93 B$ (ZFC) M vs T (FW $B=20 G$ )

$(\mathrm{Tc}=108 \mathrm{~K})$

BiPb2223 - $\mathrm{Nb}$ coated POWDER

Celanese $-\mathrm{Nb}=.5833 u m$

$\mathrm{Mb}=.5833 \mathrm{u}$

$10 / 7 / 93 \mathrm{~A}$ ( $\mathrm{ZFC}$ ) $\mathrm{M}$ vs $\mathrm{T}$ ( $\mathrm{FW} \mathrm{B}=20 \mathrm{G}$ )

BiPb2223 M vs $B$ Hysteresis ( $B$ perp) at ( $T=5 K, 10 K$ )

Celanese FC Trapped Flux. M vs $t(5 K, 10 K)$

$\mathrm{Nb}=.4166 \mathrm{u}$ FC Trapped Flux ys Applied Magnetic Field (5K, 10K)

10/7/93B (ZFC) $M$ vs T (FW $B=20 G$ )

BiPb2223 $M$ vs $B$ Hysteresis ( $B$ perp) at ( $T=5 K, 10 K$ )

$(\mathrm{Tc}=105 \mathrm{~K})$

Celanese FC Trapped Flux. M vs $t$ (5K, 10K)

$\mathrm{Nb}=.5833 \mathrm{u}$ FC Trapped Flux vs Applied Magnetic Field (5K, 10K) 
Table 5. Concluded.

10/14/93B (ZFC) $\mathrm{M}$ vs $\mathrm{T}$ (FW $\mathrm{B=20G)}$

( $\mathrm{Tc}=108 \mathrm{~K})$

BiPb2223 - Nb coated POWDER

Celanese $-\mathrm{Nb}=.20 \mathrm{um}$

$\mathrm{Nb}=.20 \mathrm{u}$

$10 / 15 / 93 A$ (ZFC) $M$ Vs $T$ ( $F W ~ B=20 G$ )

BiPb2223 M vs H Hysteresis ( $B$ perp) at ( $T=5 \mathrm{~K}, 10 \mathrm{~K}$ )

Celanese FC Trapped Flux. M vs $t$ (5K, 10K)

$\mathrm{Nb}=.20 \mathrm{u}$ FC Trapped Flux vs Applied Magnetic Field (5K, 10K)

$300 \nabla$ bias

$10 / 27 / 93 \mathrm{Nb}$ (ZFC) $\mathrm{M}$ vs $\mathrm{T}$ (FW $\mathrm{B}=20 \mathrm{G}$ )

BiPb2223 $M$ vs $B$ Hysteresis ( $B$ perp) at ( $T=2 K, 5 K, 10 \mathrm{~K}$ )

Celanese FC Trapped Flux. M vs $t$ (2K, 5K)

$\mathrm{Nb}=.25 \mathrm{a}$ FC Trapped Flus vs Applied Magnetic Field (2K, 5K)

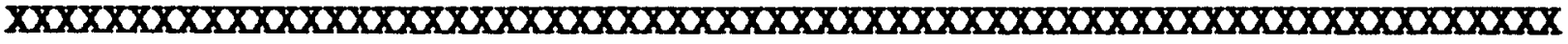

$10 / 21 / 93 A$ (ZFC) $M$ vs T (FT $\mathrm{B}=20 \mathrm{G}$ ) ( $\mathrm{TC=105 \textrm {K } )}$

BiPb2223 Ag, Nb coated POWDER

$(\mathrm{Tc}=105 \mathrm{~K})$

Celanese

$\mathrm{Ag}=.28 \mathrm{um}$

$\mathrm{Nb}=.30 \mathrm{um}(300 \mathrm{~V}$ bias)

$10 / 22 / 93 A$ (ZFC) $\mathrm{M}$ Vs $T$ ( $F H ~ B=20 G$ )

BiPb2223 $M$ vs $B$ Hysteresis ( $\mathrm{B}$ perp) at ( $\mathrm{T}=2 \mathrm{~K}, 5 \mathrm{~K}, 10 \mathrm{~K}$ )

Celanese FC Trapped Flux. M vs $t$ (2K, 5K)

Ag=.28um FC Trapped Flux vs Applied Magnetic Field (2K, 5K)

$\mathrm{Nb}=.30 \mathrm{um}$ ( $300 \mathrm{~V}$ bias)

$10 / 27 / 93$ (ZFC) $M$ vs $T$ (FW $\mathrm{B}=20 \mathrm{G}$ )

$(\mathrm{Tc}=105 \mathrm{~K})$

BiPb2223 $M$ vs $B$ Hysteresis ( $\mathrm{H}$ perp) at ( $\mathrm{T}=2 \mathrm{~K}, 5 \mathrm{~K}, 10 \mathrm{~K}$ )

Celanese FC Trapped Flux. $M$ ys $t(2 \mathrm{~K}, 5 \mathrm{~K}, 10 \mathrm{~K})$

Ag=.28um FC Trapped Flux vs Applied Magnetic Field (2K)

$\mathrm{Nb}=.30 \mathrm{um}$ (300v bias). 


\section{DISTRIBUTION LIST}

\section{AUL/LSE}

Bldg 1405 - 600 Chennault Circle

Maxwell AFB, AL 36112-6424

1 cy

DTIC/OCP

8725 John J. Kingman Rd Ste 944

FT Belvoir, VA 22060-6218

2 cys

AFSAA/SAI

1580 Air Force Pentagon

Washington, DC 20330-1580

$1 \mathrm{cy}$

PL/SUL

Kirtland AFB, NM 87117-5776

2 cys

PL/HO

Kirtland AFB, NM 87117-5776

$1 \mathrm{cy}$

Official Record Copy

PL/VTP/Marko Stoyanof

2 cys

Dr. R. V. Wick

$1 \mathrm{cy}$

$\mathrm{PL} / \mathrm{VT}$

Kirtland, AFB, NM 87117-5776 